\title{
Airmass analysis of the processes driving the progression of the Indian summer monsoon
}

Article

Published Version

Creative Commons: Attribution 4.0 (CC-BY)

Open Access

Volonté, A., Turner, A. G. ORCID: https://orcid.org/0000-00020642-6876 and Menon, A. (2020) Airmass analysis of the processes driving the progression of the Indian summer monsoon. Quarterly Journal of the Royal Meteorological Society, 146 (731). pp. 2949-2980. ISSN 1477-870X doi: https://doi.org/10.1002/qj.3700 Available at https://centaur.reading.ac.uk/84113/

It is advisable to refer to the publisher's version if you intend to cite from the work. See Guidance on citing.

To link to this article DOI: http://dx.doi.org/10.1002/qj.3700

Publisher: Royal Meteorological Society

All outputs in CentAUR are protected by Intellectual Property Rights law, including copyright law. Copyright and IPR is retained by the creators or other copyright holders. Terms and conditions for use of this material are defined in the End User Agreement. 


\section{CentAUR}

Central Archive at the University of Reading

Reading's research outputs online 
modelling, PV streamers, Lagrangian trajectories, diabatic processes

\section{1 | INTRODUCTION}

The Indian summer monsoon (ISM) is a vital source of water for more than a billion people in the Indian subcontinent. Agricultural, industrial and economic development are largely dependent on monsoon rainfall, as are basic human and societal needs for the populations of India, Pakistan and neighbouring countries. Variability in monsoon rainfall can also lead to large impacts, as major droughts (Bhat, 2006) and devastating floods (Houze et al., 2011) remind us. Therefore, research investigating the mechanisms driving the onset and progression of the ISM and those affecting its intensity can be of substantial benefit to society. The INCOMPASS project (Interaction of Convective Organisation with Monsoon Precipitation, Atmosphere, Surface and Sea), see Turner et al. (2019), has been designed to tackle these challenges, through an observational field campaign supplemented by high-resolution convection-permitting numerical simulations for the 2016 season.

The main driver of the ISM is the seasonal cycle of solar heating that warms land regions in South and Southeast Asia faster than neighbouring oceans during boreal spring. The resulting meridional temperature and pressure gradients trigger a cross-equatorial surface flow and a return flow aloft (Turner and Annamalai, 2012). However, the ISM dynamics cannot be reduced to the simple idea of a continental-scale land-sea breeze circulation, as the elevation of the Himalaya and Tibetan Plateau ensures that the large-scale meridional temperature gradient generated by this difference in sensible heating exists over a significant depth of the troposphere (Li and Yanai, 1996). The Himalaya also has a role in separating tropical high-MSE (moist static energy) air from dry continental low-MSE flow, thus helping in setting the poleward extension of the monsoon and strengthening its circulation (Boos and Kuang, 2010). This seasonal cycle in

solar heating can also be seen as a northward shift of the inter-tropical convergence zone (ITCZ), with the equatorial convection moving poleward along with the associated lower-tropospheric moist cross-equatorial flow (Webster et al., 1998).

The ISM onset, traditionally declared by the India Meteorological Department (IMD) on the arrival of sustained rainfall over Kerala (Menon et al., 2018), can be considered the result of this northward propagation of the ITCZ (Gadgil, 2003). Onset indices based on rainfall over India have been introduced (Noska and Misra, 2016). Alternatively, the ISM onset can be defined by looking at the reversal of meridional temperature gradient south of the Tibetan Plateau through most of the troposphere. This is a consequence of the strong sensible heating occurring over the Plateau, while the condensational heating occurring over the Indian Ocean is offset by the adiabatic cooling of ascending air (Li and Yanai, 1996). Fasullo and Webster (2003) suggest instead the use of vertically integrated moisture transport (VIMT) to diagnose onset and withdrawal of the ISM, as they argue that large transport of water vapour is a consequence of the temperature gradient and a necessary ingredient for monsoonal rain. Furthermore, VIMT is generally better observed than rainfall on the large-scale and is thus the preferred choice to link the monsoon onset with its atmospheric and hydrological basis. Also Xavier et al. (2007) focus on the large-scale meridional heating gradient, as they define ISM onset (withdrawal) as the day when the tropospheric heat source shifts from south to north (north to south). Several other onset indices have been suggested in recent years (Menon et al., 2018), all describing the interannual variability of the ISM. Rainfall variability on intraseasonal timescales (the so-called "active" or "break" phases of the ISM) adds to the interannual variations, often causing the largest impacts in terms of drought and flood events (Turner and Annamalai, 2012). The concept of intraseasonal variability helps to introduce the idea of monsoon progression as a non-steady process, composed by "hiatus" and "advance" stages, in the terminology used by the IMD. The main drivers of this

This article is protected by copyright. All rights reserved. 
progression will be briefly described in the next paragraphs.

One of the main features playing a role in ISM onset and progression is the low-level jet that carries moisture from the Indian Ocean towards the Indian subcontinent, crosses the equator with a northward orientation and then gradually rotates to the east over the Arabian Sea, becoming a southwesterly or even westerly jet (Findlater, 1969). It is also known as the Somali jet, as its path is anchored by the presence of the meridionally-oriented East African Highlands (Hoskins and Rodwell, 1995) while its anticyclonic turning is favoured by the Earth's rotation. Boos and Emanuel (2009) show that the speed of low-level southwesterlies over the Arabian Sea increases faster than could be expected by taking into account forcing from solar heating alone. The Somali Jet has a focused core near the orography of east Africa. During its onset, substantial and nearly co-located increases of low-level southwesterlies, deep tropospheric ascent, and surface enthalpy fluxes are observed over the Arabian Sea, while peak free-tropospheric temperatures are found poleward. This finding is consistent with a wind-evaporation feedback and suggests that wind-driven evaporation could be causing the rapid intensification in circulation and convective rainfall over the Arabian Sea during ISM onset. The rainfall associated with this advection of moisture is enhanced in mountain regions, such as the Western Ghats on the west coast of India. Also the warmer sea surface temperature (SST) over the Bay of Bengal contributes to the zonal asymmetry of precipitation in the ISM region (Shenoi et al., 2002). A large proportion of the rainfall observed, particularly over northeastern peninsular India, comes in the form of mesoscale convective systems embedded in the monsoon trough. These organised convective structures are normally part of monsoon depressions (Hunt et al., 2016), synoptic-scale cyclonic systems usually originating over the northern Bay of Bengal and propagating northwestward through the monsoon trough onto the Indian subcontinent.

Another main feature in ISM dynamics is the presence of dry mid-tropospheric air over arid land to the west of the monsoon region, whose advection towards the Indian subcontinent is associated with extratropical circulation. A clear example of the effect of the advection of dry air towards India from the west is the 2009 ISM, which resulted in a major drought year. Standard oceanic predictors like ENSO and the Indian Ocean dipole, as well as other parameters, were not consistent with the occurrence of a dry monsoon season. However, the formation of a blocking high over western Asia led to advection of descending and very dry air towards central India. This incursion of mid-tropospheric dry air from the deserts had the consequence of strongly inhibiting deep convection (Krishnamurti et al., 2010). Hence, before focusing on the characteristics of this dry-air incursion (see next paragraph), it is necessary to stress that there is in fact a connection between extratropics and monsoon region, as Rodwell and Hoskins (1996) point out. Highlighting the so-called 'monsoon-desert' mechanism, they show how diabatic heating in the Asian monsoon region can induce a Rossby-wave pattern to the west, associated with adiabatically-descending mid-latitude westerlies. Vellore et al. (2016) expand on this concept, outlining the key elements of monsoon-extratropics interactions conducive to heavy rainfall events in the Himalaya region. They focus on the interaction between a deep southward-penetrating mid-latitude westerly trough, possibly associated with Rossby wave breaking, and the west-northwest propagation over the Indian subcontinent of monsoon low-pressure systems, along with the effect of the orography on circulation and convection, as a primary driver of heavy monsoon rainfall. The existence of this monsoon-extratropics interaction is confirmed by the fact that cyclonic PV anomalies on the subtropical jet over west Asia and low-level anticyclonic circulation over the north Arabian Sea are indeed associated with the advection of air masses with climatologically low PV and humidity southeastward, towards central India and the core of the ISM region (Fletcher et al., 2018). In consequence, the mid-latitude circulation could be a primary source of short-term variability in the progression of the ISM, in a similar way to what happens for the Australian monsoon where active phases ("bursts") are preceded by the development of a well-defined extratropical wave packet in the Indian Ocean, propagating toward the Australian continent and leading to the onset of heavy rainfall in the tropics (Berry and Reeder, 2016).

The dynamics with which this dry-air incursion affects the progression of the moist low-level monsoon flow is

This article is protected by copyright. All rights reserved. 
investigated in detail in Parker et al. (2016), using observations and reanalysis data. Their study addresses the apparent contradiction between the direction of the low-level monsoon flow, which is mainly southwesterly to westerly, and the progression of the monsoon rains, in a northwest direction, hence perpendicular to the low-level flow and the associated moisture flux. The results in Parker et al. (2016) show that the mid-level northwesterly flow forms a wedge of dry air, deeper in the northwest edge of India, that over-runs the moist southwesterly flow. This dry layer is moistened from below by shallow convection which gradually reduces the depth of the dry wedge, particularly in the southeast of India. Monsoon onset occurs when the dry layer is shallow enough to allow deep convection to form; as the advection of moisture from the Arabian Sea becomes stronger and the mid-level dry advection weakens, the monsoon advances towards northwest India. Hence, Parker et al. (2016) describe a gradual process to explain the northwestward propagation of the monsoon onset, whereby the dry air is eroded from below, reinforced by surface wetting associated with rainfall. Subsequent analysis, expanding on the results in Parker et al. (2016) and looking at additional effects of these dry-air incursions is now being performed. For instance, Fletcher et al. (2018) look at the interaction between dry incursions and monsoon depressions, finding the westward propagation of monsoon depressions is likely to be slowed and partially weakened by the encounter with a layer of dry and anticyclonic westerly flow. However, as Parker et al. (2016) acknowledge, more detailed analyses, through observation and high-resolution numerical simulations, are necessary. Key open questions concern the interaction of these dry-air incursions with moist low-level monsoon flow, along with the relative effects of large-scale advection, local dynamics and diabatic processes. These research questions are tackled in the present study, as outlined below.

As already mentioned, Krishnamurti et al. (2010) investigate the relationship between the presence of a blocking high over western Asia and the associated advection of dry air towards India. Martius et al. (2013) also highlight this large-scale connection between the monsoon and mid-latitudes for a very different situation, namely the Pakistan floods of July-August 2010. They show the link between a series of blocking anticyclones dominating the upper-level flow over western Russia and associated breaking waves along their downstream flank with the anomalously high moisture transport from the Indian Ocean and Bay of Bengal towards Pakistan, with very little dry advection from the northwest. Both studies make extensive use of Lagrangian trajectories to highlight the pathways of relevant air masses and the source regions of the advected moisture. In light of these studies, we start the investigation of the relationship between dry-air incursions and moist low-level monsoon flow during the onset of the 2016 ISM by looking, both with Luerian and Lagrangian methods, at the large-scale setting and at its possible links with evolution of airmasses. In this part of the study we use global forecast data from the UK Met Office (Martin et al., 2019).

Secondly, we analyse the output of the high-resolution simulations to look in detail at the tropospheric evolution in the region where the dry-air incursion meets the low-level moist monsoonal flow. Using data from high-resolution convection-permitting numerical simulations for the 2016 season performed within the INCOMPASS project, we assess the validity of the conceptual model of evolution outlined in Parker et al. (2016). Again using Eulerian and Lagrangian methods we look at the evolution of the two different air layers to see if it is possible to identify the progressive moistening of the lower troposphere with the associated increase in the depth of convection. Particular attention is devoted to whether monsoon progression can be described as progressive or instead as a non-steady process, linking it to the time variations of its drivers. We also focus on the diabatic processes taking place on the relevant airstreams during their interaction and in their antecedent path, taking into account surface and ocean effects.

To summarise, using the 2016 season as a case study, this work provides a detailed description of the dynamics from large to local scale - driving the onset and progression of the ISM, with particular focus on the evolution of the main air masses in the region. The article is organised as follows. Section 2 contains the description of the model, observation and reanalysis datasets used, along with a description of the use of Lagrangian trajectories as a method of analysis. Section 3 follows with a verification of the model output by comparing it with observations and reanalysis. The results of

This article is protected by copyright. All rights reserved. 
(a) Model Orography in the Global UKMO Forecasts $(\mathrm{m})$

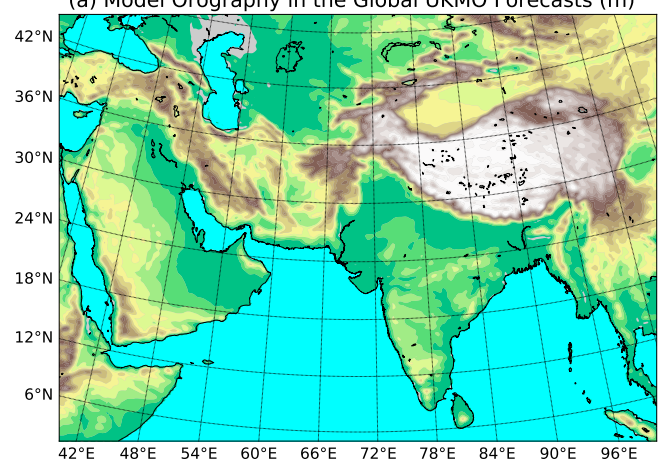

(b) Model Orography in the INCOMPASS $4.4 \mathrm{~km}$ LAM (m)

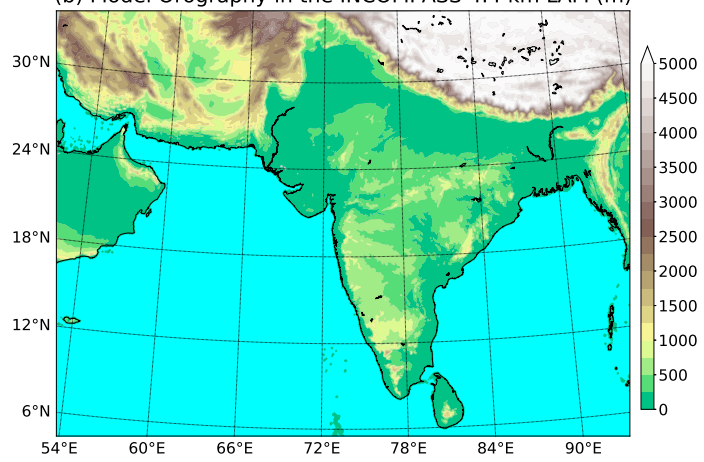

FIGURE 1 Model orography (a) in the section of the domain of interest to this study of the MetUM global forecasts and (b) in the domain of the $4.4 \mathrm{~km}$ resolution limited area model (LAM) simulation.

(3)

the study, i.e. the global and local perspective of the analysis on the evolution of the air masses are presented in Sections 4 and 5 , respectively. Section 6 concludes the study with a summary of the main results.

\section{I DATA AND METHODS}

This section contains a description of global and regional models used in the study, along with observation and reanalysis

datasets and introduces the concept of Lagrangian analysis as a post-processing method of the model output.

1

\section{1 | Global model}

Global data used in this study are obtained from operational forecasts run by the UK Met Office using the Met Office Unified Model (MetUM). The MetUM is a non-hydrostatic fully compressible model with deep atmosphere dynamics. The operational weather forecasting model version in use in 2016 was the GA6.1/GL6.1 science configuration (Walters et al., 2017) operating at a horizontal resolution of N768 $(17 \mathrm{~km})$ with 70 vertical levels and model lid at $80 \mathrm{~km}$. The horizontal latitude-longitude grid uses an Arakawa C-grid staggering (Arakawa and Lamb, 1977) and a terrain-following hybrid-height Charney-Phillips vertical grid (Charney and Phillips, 1953). This version includes the Even Newer Dynamics for General Atmosphere Modelling of the Environment (END Game) dynamical core (Wood et al., 2014) and a prognostic cloud fraction and condensation (PC2) scheme (Wilson et al., 2008). Deep and shallow convection are parametrised, respectively, using a bulk mass flux scheme developed by Gregory and Rowntree (1990) and a scheme by Grant (2001). More details on the convective parametrisation, along with other parametrisations used in the model, can be found in Martin et al. (2019).

The set of data used in this study contains the first 24 hours of each 00 UTC forecast from 01 June to 30 June. We chose to use short-lead-time operational forecasts as opposed to model analyses as for the former we had access, via the UK Met Office archive, to more fields and with a higher sampling frequency (essential for the computation of Lagrangian trajectories). The decision to consider for each day only the first 24 hours of the same-day operational forecast ensures that the data considered would still be consistent with a model analysis valid for the same time.

This article is protected by copyright. All rights reserved. 


\section{2 | Limited Area Model (LAM)}

In addition to global forecast data, this study makes use of MetUM-based seasonal LAM simulations specifically generated for the INCOMPASS project (Turner et al., 2019). Nested suite limited-area model (LAM) simulations were performed for the summer months of 2016 , from 01 May to 30 September, for the Indian region $50^{\circ} \mathrm{E}-100^{\circ} \mathrm{E}$ and $5^{\circ} \mathrm{N}$ $35^{\circ} \mathrm{N}$ (model domain shown in Figure 1b). The LAM simulation used in this study has a horizontal resolution of $4.4 \mathrm{~km}$ and 80 vertical levels, with its lid at $38.5 \mathrm{~km}$. Boundary conditions are provided by the driving global MetUM at N768 resolution, initialised daily from the global analysis while the LAM is allowed to run freely within their domain. Also in this case, model output has been converted to 15-hPa spaced pressure levels.

The main difference between the model physics of this regional simulation and the global forecasts resides in the treatment of convection, explicit in the high-resolution LAM and parametrised in the global forecasts. Another difference is in the cloud scheme as, following recent similar studies (see Stratton et al. (2018) among others), the LAM uses the diagnostic scheme in Smith (1990) instead of the prognostic PC2 scheme. Despite the high resolution of the LAM, there is still a comprehensive set of parametrisations for processes too complex or small-scale to be physically represented in the model, such as surface exchange (Essery et al., 2001), boundary-layer mixing (Lock et al., 2000), mixed-phase cloud microphysics (Wilson and Ballard, 1999), and long-wave and short-wave radiation (Edwards and Slingo, 1996). Boundary layer turbulence is parametrised using a blended scheme (Boutle et al., 2014) that combines the one-dimensional (1D) scheme (Lock et al., 2000) with 3D Smagorinsky. Sea surface temperature is updated daily using the Operational Sea Surface Temperature and Sea Ice (OSTIA) analysis (Donlon et al., 2012). The surface boundary conditions are provided through the land ancillaries. Both the $17 \mathrm{~km}$ and $4 \mathrm{~km}$ simulations use land-sea mask, soil properties, vegetation cover etc. from the International Geosphere and Biosphere Programme (IGBP) dataset (Loveland et al., 2000), which has a resolution of about $1 \mathrm{~km}$ globally.

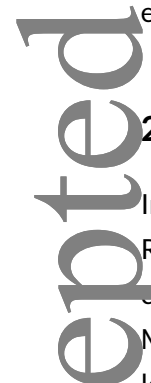

\subsection{Other datasets from observations and reanalysis}

In Section 3 observations and reanalysis data are used to verify the fidelity of the LAM simulation output (Section 2.2). Rainfall observations are provided by the satellite-gauge merged daily precipitation dataset (Mitra et al., 2009, 2013) , nbining Multi-satellite Precipitation Analysis (TMPA) satellite estimates, part of the Tropical Rainfall Measuring Mission (TRMM), with the joint National Centre for Medium-Range Weather Forecasts (NCMWRF) and India Meteorological Department (IMD) gridded rain gauge dataset. The horizontal resolution of this product is $0.25^{\circ}$. Reanalysis rainfall data are instead provided by the ERA5 dataset (Hersbach et al., 2018), with the same horizontal resolution of $0.25^{\circ}$.

Observational vertical profiles of the atmosphere are provided by the radiosondes launched within the INCOMPASS campaign. In fact, during the field campaign additional launches and radiosonde sites were added to the network of IMD radiosondes, see Turner et al. (2019) for further details.

\subsection{The use of Lagrangian trajectories}

Lagrangian methods, such as backward and forward trajectories, are a useful tool for studies investigating the evolution of air masses, their pathways and source regions, the variations in quantity transported and the processes happening along the flow. Lagrangian trajectories have been widely used in recent studies across a number of scales, from the large-scale subtropical jet (Martius, 2014), the evolution of warm conveyor belts along storm tracks (Madonna et al., 2014; Pfahl et al., 2014) all the way down to mesoscale phenomena such as the occurrence of symmetric instability

This article is protected by copyright. All rights reserved. 
in sting jets (Volonté et al., 2018). Lagrangian methods have also been used to inspect the atmospheric water cycle and develop moisture source diagnostics (Sodemann et al., 2008). While most of these studies focus on extratropical dynamics, some of them have taken advantage of the use of Lagrangian trajectories to analyse features of the ISM, e.g. Parker et al. (2016), Martius et al. (2013) and Krishnamurti et al. (2010) (see Section 4.4 for more details). This study makes extensive uses of Lagrangian trajectories, building on methods used in both tropical and extratropical studies. Here, trajectories are computed using the LAGRANTO Lagrangian analysis tool (Wernli and Davies, 1997; Sprenger and Wernli, 2015). LAGRANTO uses an iterative Euler scheme with an iteration step equal to $1 / 12$ of the time spacing of the input data, which is hourly for the LAM simulation and 3-hourly for the global forecast data.

\section{5 | Post-processing software}

The software NDdiag (Panagi, 2011) has been used to convert the model output to 15-hPa spaced pressure levels and to compute further diagnostic fields (see Volonté et al. (2018) and Grams and Archambault (2016) for examples of its use in the literature).

\section{3 | RESULTS: VALIDATION AGAINST OBSERVATIONS}

The detailed model analysis of the evolution of the ISM in June 2016 constitutes the core of this study. Therefore, it is important to verify the reliability of these model simulations in representing the aforementioned evolution. For this reason, observational and reanalysis daily rainfall datasets are compared to the output data from the LAM simulation, along with radiosonde vertical profiles. The same comparison is not shown for the global MetUM operational forecasts because, as explained in Section 2.1, the short lead time of these forecasts data prevents them from drifting away from observations / model analysis.

Figure 2 shows the 5 -day average daily rainfall over the Indian subcontinent according to the LAM simulation (left), ERA5 reanalysis (centre) and the NCMRWF/IMD merged satellite - rain gauge datasets (see Section 2.3 for more details). The different rows contain four 5-day periods that cover most of June 2016 and illustrate the progression of tIt ISM. The top panels do not display any rain over NW India while the bottom ones show widespread rain over most of the subcontinent. Differences in resolution ( $4.4 \mathrm{~km}$ horizontal grid spacing for the LAM and $25 \mathrm{~km}$ for both reanalysis and observations) produce differences in the structure of the rainfall patterns, with much more fine structure resolved by the LAM, particularly when considering single-cell convection over the ocean. Apart from that, and from a reduction of rainfall over the northern Bay of Bengal in the LAM in initial stages, the good agreement between the three datasets stands out.

All columns of Figure 2 reveal an initial reduction in daily rainfall over SE India between the first and second rows, suggesting a temporary retreat of the monsoon between the 5-day periods centred around 10 June and 15 June, respectively. In the same way, all datasets display a sudden increase of daily rainfall in the following 5 days, with widespread rain covering most of India and leaving out only its northwestern corner. Rainfall does indeed fill this corner by the final 5 days, as shown by all panels in the last row, indicating a substantial evolution towards a mature monsoon.

Hence, the LAM simulation is consistent with observations and reanalysis in depicting the evolution of daily rainfall during June 2016, apart from minor differences. In addition to this, all sources reveal that this progression is clearly non-steady, with jumps and retreats. It is worth remarking, even though this is not of direct interest to this study, that the LAM simulation clearly displays the two phases of offshore and onshore rainfall with respect to the west coast of India and the Western Ghats mountains investigated in Fletcher et al. (2019).

This article is protected by copyright. All rights reserved. 
(b) GWA - 13 June 12 UTC

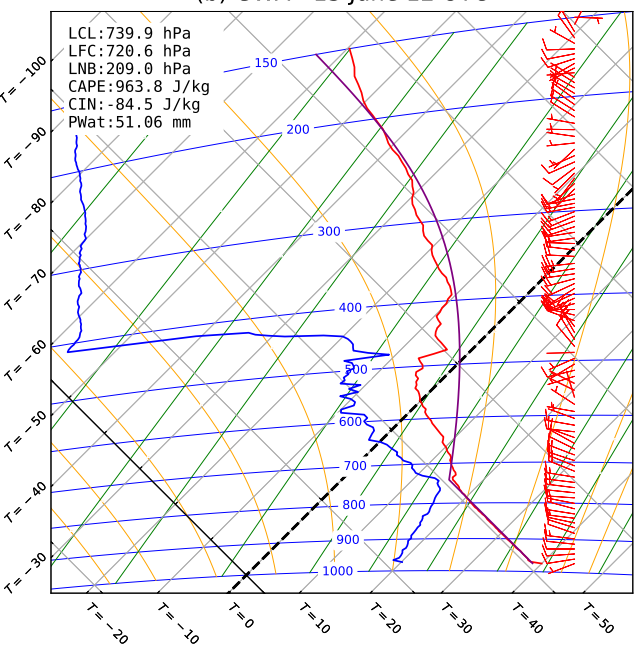

(b) GWA - 28 June 12 UTC

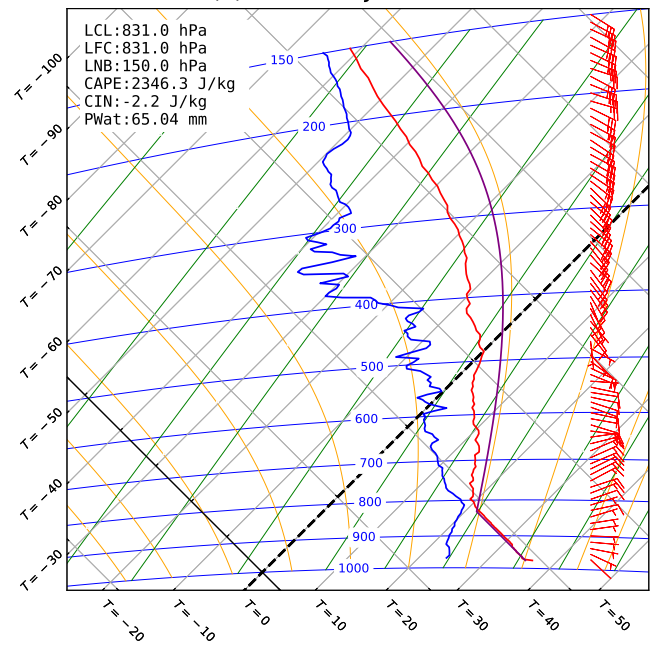

(b) HYD - 13 June 12 UTC

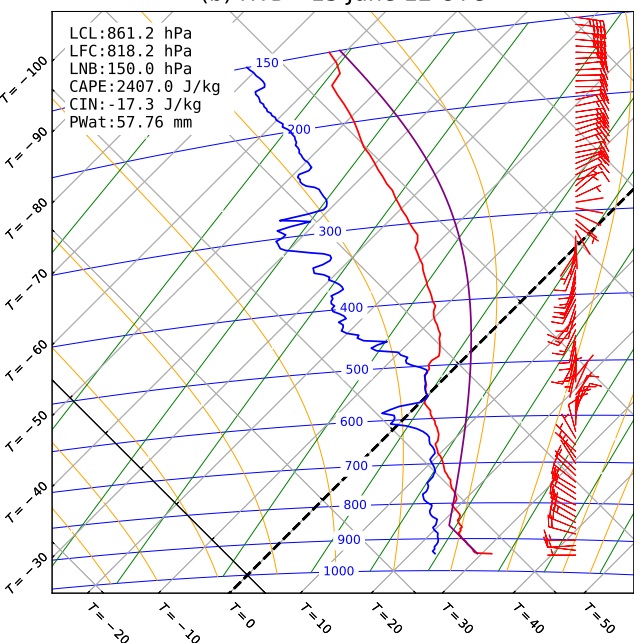

(b) HYD - 28 June 12 UTC

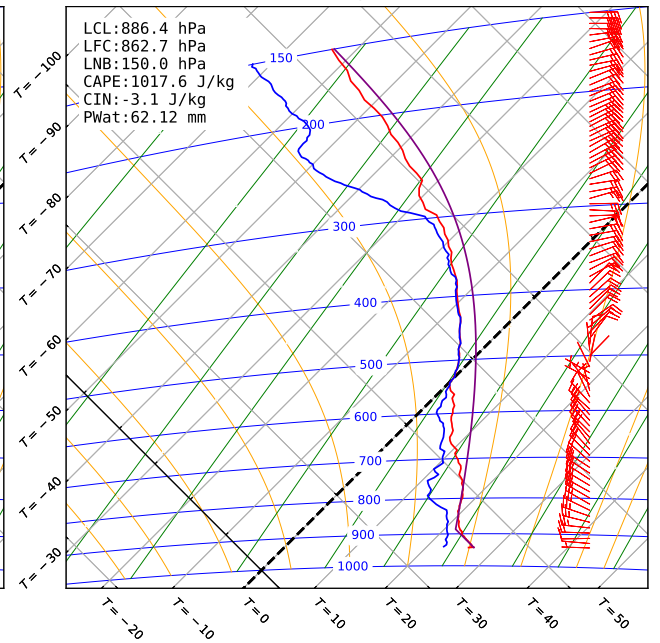

FIGURE 3 Thermodynamic profiles (tephigrams) from radiosondes launched at Gwalior and Hyderabad (see Figure 2 for their locations) at 12 UTC (17:30 IST) on 13 and 28 June 2016 (see text for more details). Solid lines indicate environmental dry-bulb temperature (red), environmental dew-point temperature (blue) and ascending-parcel temperature (magenta). Thermodynamic indices in the top-left box are computed using virtual temperatures. Isolines included in the profiles are isotherms (grey upper right - lower left lines, solid black for $\mathrm{T}=0^{\circ} \mathrm{C}$ ), dry adiabats (grey upper left - lower right lines, solid black for $\theta=0^{\circ} \mathrm{C}$ ), wet adiabats (yellow lines) and constant mixing ratio lines (green lines). Red barbs indicate wind direction (upward-pointing for southerly wind) and strength (full feather $=5 \mathrm{~m} \mathrm{~s}^{-1}$, half feather $=2.5 \mathrm{~m} \mathrm{~s}^{-1}$ ).

June 2016. The top panels (referred to 13 June) illustrate well the difference between pre-onset conditions in Gwalior as opposed to post-onset in Hyderabad. In fact, the profile over Gwalior has a surface temperature of $40{ }^{\circ} \mathrm{C}$ and a dry-adiabatic lapse rate in the low levels, indicating strong surface heating in non-saturated conditions. The saturation 
(a) GWA - 13 June 12 UTC

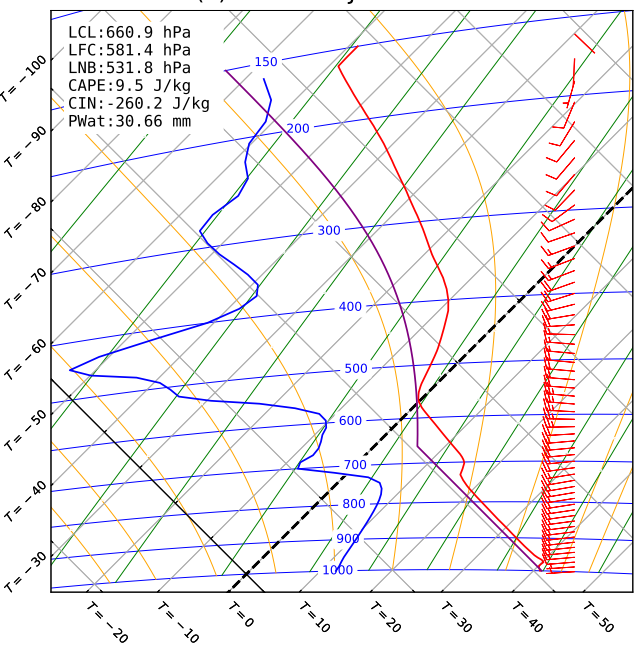

(c) GWA - 28 June 12 UTC

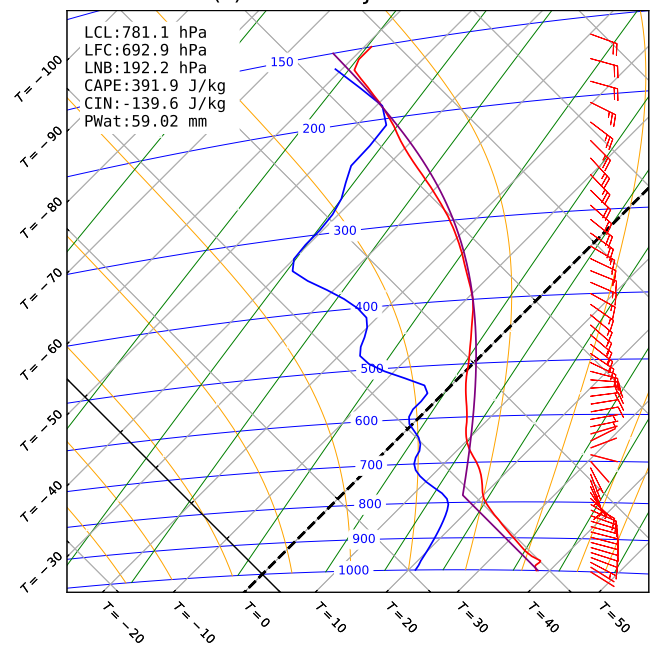

(b) HYD - 13 June 12 UTC

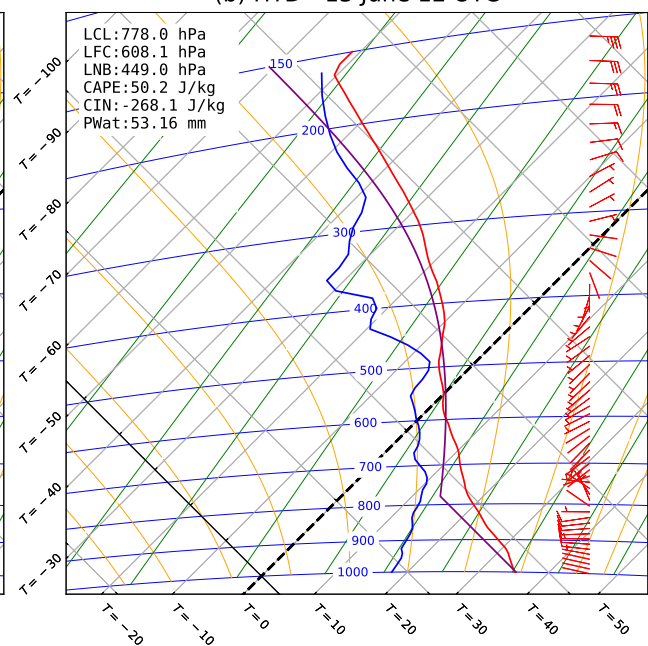

(d) HYD - 28 June 12 UTC

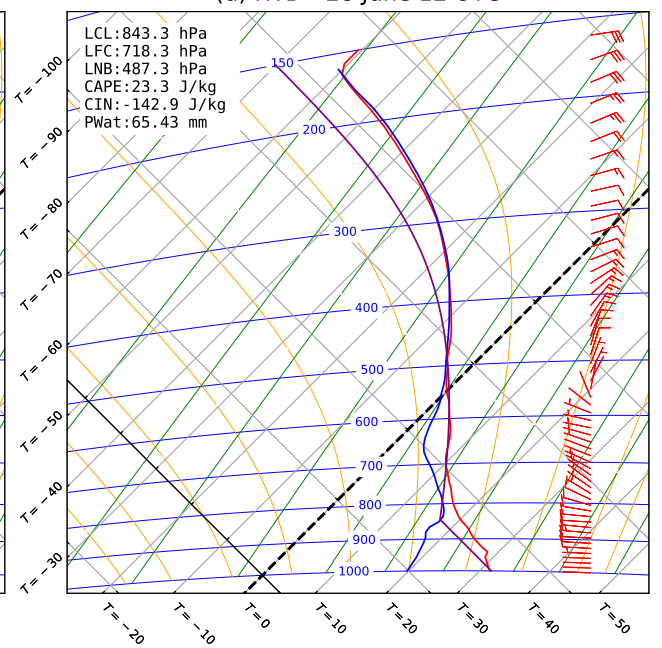

F I G URE 4 Thermodynamic profiles (tephigrams) from LAM simulation data computed at Gwalior and Hyderabad (see Figure 2 for their locations) at 12 UTC on 13 and 28 June 2016 (see text for more details). Solid lines indicate environmental dry-bulb temperature (red), environmental dew-point temperature (blue) and ascending-parcel temperature (magenta). Thermodynamic indices in the top-left box are computed using virtual temperatures. Isolines included in the profiles are isotherms (grey upper right - lower left lines, solid black for $\mathrm{T}=0^{\circ} \mathrm{C}$ ), dry adiabats (grey upper left - lower right lines, solid black for $\theta=0^{\circ} \mathrm{C}$ ), wet adiabats (yellow lines) and constant mixing ratio lines (green lines). Red barbs indicate wind direction (upward-pointing for southerly wind) and strength (full feather $=5 \mathrm{~m} \mathrm{~s}^{-1}$, half feather $=2.5 \mathrm{~m} \mathrm{~s}^{-1}$ ).

is reached at around $750 \mathrm{hPa}$, where a small amount of CIN (Convective Inhibition) is detected below the LCL (Lifting Condensation Level). Above this small convective inhibition, there is a substantial amount of CAPE (Convective Available Potential Energy), conducive to convection. Drier air is present in the upper half of the troposphere, with a marked spike 
in dew-point temperature at around $400 \mathrm{hPa}$. Moisture content above that spike cannot be safely inferred from the tephigram as it is likely that the sensor stopped measuring correctly above the aforementioned spike. The profile over Hyderabad is substantially closer to saturation, particularly in the mid - and upper - troposphere. This latter profile shows very high values of CAPE, close to $2500 \mathrm{~J} / \mathrm{kg}$, and negligible CIN, suggesting the likely occurrence of intense deep convection.

The bottom panels, referred to 28 June, clearly indicate that the monsoon onset has already occurred in both locations and that the monsoon is evolving towards a more well-developed stage. In the profile over Gwalior the non-saturated dry-adiabatic layer at low levels has become shallower, with the LCL around $100 \mathrm{hPa}$ lower than on 13 June. The amount of CAPE has substantially increased to well above $2000 \mathrm{~J} / \mathrm{kg}$ and, with negligible inhibition, intense deep convection is very likely to occur. Clear moistening of the upper troposphere is visible. This upper-tropospheric moistening is also indicated in the profile over Hyderabad, where the whole profile from the surface up to $300 \mathrm{hPa}$ is at - or close to - saturation. Again, the absence of inhibition and the high values of CAPE indicate a favourable environment for deep convection. PWat (Precipitable Water) has increased from 13 to 28 June in both locations, indicating a deepening of the moist advection associated with the monsoon. Low-level westerlies indeed increase their depth by more than $100 \mathrm{hPa}$ over Hyderabad, while over Gwalior (located at a higher latitude) low-level winds reverse from westerlies to easterlies, indicating the development of the monsoon trough. At upper levels the easterlies associated with the return flow of the monsoon circulation are developing, extending down to the mid-troposphere in both locations.

Figure 4 shows vertical profiles that are equivalent to the radiosonde ones in Figure 3 but generated with data from the LAM simulation by selecting the nearest gridpoint to the launch location. These profiles are broadly consistent with their observational counterparts. Most of the troposphere over Gwalior increases its moisture over time, with a weakening of the dry spike, while the troposphere over Hyderabad, particularly its upper half, moves close to saturation. The wind vertical structure is also mostly consistent between observed and simulated profiles, with both sources showing a transition to easterlies of upper - and mid - level winds and the deepening of the low-level moist westerlies over Hyderabad.

The main difference between the profiles in Figure 3 and Figure 4 is that the simulated profiles are more stable. CAPE values are substantially lower than in radiosonde profiles, with increased inhibition and raised LCL height. This could be due to a negative bias in the surface and low-level moisture content, that is reflected in deeper dry-adiabat ascents. A more detailed investigation of the causes of this discrepancy goes beyond the scope of this work. Despite this difference in stability, the agreement between model and radiosonde profiles can be deemed satisfactory as the overall evolution of the vertical structure in both location is correctly depicted. It is also necessary to consider that some discrepancies were to be expected in any case, as the comparison is performed on single-point measurements rather than regionally as done for rainfall and also as real radiosondes would drift outside the gridpoint columns according to the winds.

In conclusion, model simulations provide a suitable level of fidelity to observations to justify a model investigation of the progression of the ISM during June 2016. It is also important to note that the analysis of 5-day mean daily rainfall indicates that variability plays a key role in ISM progression, suggesting that this process is inherently unsteady. This hypothesis is verified in Sections 4 and 5, by performing a large-scale and then a regional analysis, respectively.

This article is protected by copyright. All rights reserved. 


\section{4 | RESULTS: LARGE-SCALE ANALYSIS}

Here the analysis of global MetUM forecast data (Section 2.1) is presented. This part of the study aims to highlight any relationship between the onset and progression of the 2016 ISM and the large-scale situation, focusing on the dynamics of the air masses driving this process. The results presented here reveal how monsoon progression, i.e. the competition between retreating dry subtropical air and advancing moist tropical air, is in fact a non-steady process.

\section{1 | Overview of progression and interaction with mid-latitude flow}

In order to examine the large-scale behaviour through the ISM onset, Figure 5 shows geopotential height, winds and temperature from the global MetUM forecast data on the $625 \mathrm{hPa}$ pressure level at $06 \mathrm{UTC}$ every 3 days, from 10 to 25 June 2016. The advection of tropical air in the ISM circulation occurs mainly in the lower troposphere, whereas extratropical motions are commonly detected at higher altitudes. Therefore, we select an intermediate pressure level to highlight the evolution of both tropical and mid-latitude air masses. This figure also contains a smoothed representation of the subtropical upper-level jet configuration, computed by looking at maximum wind speed at $220 \mathrm{hPa}$, the level at which the jet-stream was most consistently detected in the period considered.

Initial straight southwesterly flow travelling from Egypt towards central Asia is visible in Figure 5a (10 June), while a trough located over the Caspian Sea provides a large meridional oscillation to this flow, as seen in Figure 5b. The passage of this trough on 13 June is associated with the development of zonal flow over the Persian Gulf and Iran, where a maximum in mid-tropospheric temperature can be found. On the contrary, the southwesterly flow crossing the equator over the Indian Ocean and then turning anticyclonically towards southern India does not seem to be initially affected by this higher-latitude dynamics. However, the subsequent panels show that the meridional oscillation in the subtropical jet does affect the flow in the Arabian Sea and towards India. In fact, in Figure 5c (16 June) a cyclonic structure can be seen forming over the southeastern tip of the Arabian Peninsula, close to where the temperature maxima could be found in previous panels. The passage of a second trough, visible in Figure $5 c$ over the Black Sea and the Middle East region is associated with northwesterly flow that might also be playing a role in reinforcing the cyclonic circulation just mentioned. It is worth noting at this point that no meridional flow from the equator moves towards southern India, with only the southern tip of Kerala reached by zonal flow crossing the Indian Ocean. At the same time northerly flow develops behind the first trough advecting mid-latitude air from central Asia towards Pakistan and pushing towards northern India the high-temperature air previously found there. The situation in the Indian Ocean and upstream of the Indian subcontinent is thus now markedly different from the one depicted in Figure $5 \mathrm{a}$. The role of the aforementioned cyclonic circulation in preventing a monsoonal flow towards India needs to be carefully assessed, along with its link with the circulation at higher latitudes. This investigation is performed in the next sections of this article, while here the remaining panels of Figure 5 are described.

In Figure 5d (19 June) the cyclonic circulation over the northern Arabian Sea is still present and it is now flanked by another cyclonic circulation centred over central-southern India. As a result, northerly and northeasterly flow dominates over Pakistan, the southern tip of the Arabian Peninsula and off the northwestern coasts of India. No well-structured monsoonal flow towards southern India is present and zonal flow is absent over northwestern India, Iran and Pakistan, with the air masses over western Asia and Arabian Peninsula unable to reach the Indian subcontinent. The last two panels of Figure 5 (22 June and 25 June) again display a cyclonic circulation over the northern Arabian Sea, while another one develops over the Bay of Bengal. While the northerly flow over Iran and central Asia is still present (and is associated with the passage of another trough in Figure 5e), the situation in the Arabian Sea has now changed. Southwesterly flow crosses the sea, now reaching the Indian coast up to $20^{\circ} \mathrm{N}$. This zonal flow is up to $15^{\circ}$

This article is protected by copyright. All rights reserved. 
many factors, such as mid-latitude troughs and tropical cyclonic circulations, playing a role.

\section{2 | PV streamers and cyclogenesis over the monsoon region}

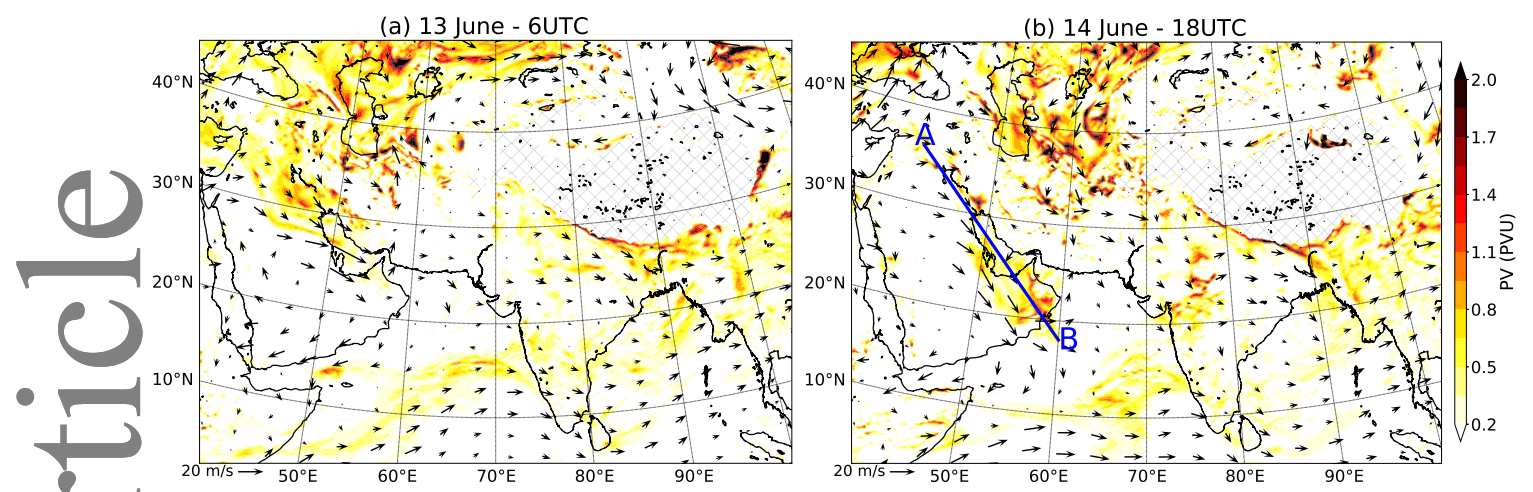

(c) cross section $A B$ on 14 June - 18UTC

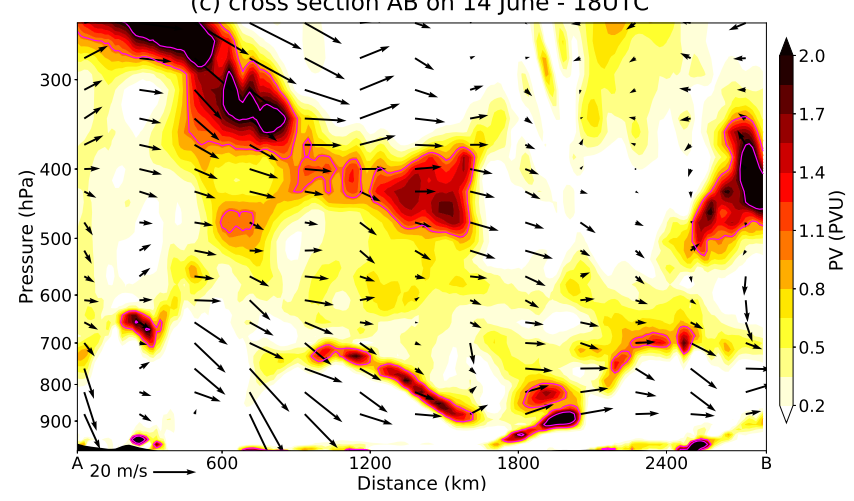

FIGURE 6 PV (shading, $1 \mathrm{PVU}=1 \times 10^{-6} \mathrm{~K} \mathrm{~kg}^{-1} \mathrm{~m}^{-1} \mathrm{~s}^{-1}$ ) and horizontal wind vectors (quivers, $\mathrm{m} \mathrm{s}^{-1}$ ) at $700 \mathrm{hPa}$ at $06 \mathrm{UTC}$ on (a) 13 June, (b) 18 UTC on 14 June 2016. (c): cross section of transect AB in panel (b). Quivers in (c) are constructed using the wind parallel to the cross-section as horizontal component and vertical velocity multiplied by 160 as vertical component. Data

from global MetUM operational forecasts initialised at 00 UTC on the same day as which each panel is labelled (Section 2.1).

As explained in Section 4.1, the progression of the 2016 ISM is substantially influenced by the development of a cyclonic circulation over the northern Arabian Sea, whose formation is preceded by the passage of a trough over central Asia (Figures $5 \mathrm{~b}$ and $5 \mathrm{c}$ ). This section inspects the existence of a dynamical link between the two features. The potential vorticity (PV) framework (Hoskins et al., 1985) is particularly useful for this task as PV, being dry-adiabaticallyconserved, can indicate the path undertaken by air masses. PV can also be used to inspect the circulations resulting from the evolution of Rossby waves. In fact, the strong deepening, and even breaking, of Rossby waves near the extratropical tropopause can lead to the formation of elongated tongues of high-PV stratospheric air that extend equatorward. Frequently, PV tongues can be further stretched into narrow filaments, so-called PV streamers, which eventually break up into separate PV cutoff vortices (Appenzeller and Davies, 1992). The 2 PVU-surface is normally used as a threshold to isolate these high-PV incursions (Wernli and Sprenger, 2007).

This article is protected by copyright. All rights reserved. 
Figures 6a and 6b show PV at 06 UTC on 13 June (same as Figure 5b) and at 18 UTC on 14 June (halfway through Figures $5 \mathrm{~b}$ and $5 \mathrm{c}$ ) at $700 \mathrm{hPa}$, level chosen as it clearly displays the evolution of PV in the lower part of the free troposphere. The PV footprint of the passage of the trough is visible in Figure 6a with higher values of PV over the region around the Caspian Sea and just north of the Persian Gulf. This latter high-PV region is associated with the development of northwesterly flow behind the trough. Figure $6 \mathrm{~b}$ shows that those high-PV values have moved equatorward, along with the associated northwesterly flow, and are now visible over the southeastern tip of the Arabian Peninsula. As the local PV-maximum at this level moves close to the genesis region of the cyclonic circulation mentioned in the previous section (see Figure $5 \mathrm{c}$ in particular, and following panels), it is worth inspecting the vertical structure of this equatorward $P V$ advection.

Figure $6 \mathrm{c}$ is a cross section evaluated on transect AB in Figure 6b, i.e. at 18 UTC on 14 June. This section displays two vertically-aligned regions of high-PV values, close to 2 PVU, over the southeastern part of the Arabian Peninsula (see location of transect). In the upper troposphere descending high-PV air is visible, associated with tropopause folding behind the trough centre and moving southeastward towards the north Arabian Sea region. Underneath it, diabatically-generated high-PV values are present in patches in the lower troposphere. Given that in the same part of the section PV values are higher than elsewhere also in the middle troposphere (although not close to 2 PVU as in lower and upper levels), we can talk about the presence of a "PV tower", i.e. a troposphere-spanning column of air with anomalously high PV values, inducing the strengthening of a cyclonic circulation (Čampa and Wernli, 2012).

Hence, the equatorward propagation of an upper-level PV streamer, associated with the passage of a mid-latitude trough over central Asia, does play a role in the development of a cyclonic circulation over the Arabian Sea. As explained in Section 4.1, this cyclonic circulation is a primary factor in influencing ISM progression in June 2016. Thus, this result confirms that monsoon progression can be influenced by large-scale extratropical dynamics.

\section{3 | Balance between moist and dry air masses}

After an initial focus on the variability of the flow over the ISM region and on the underpinning dynamical factors during this non-steady monsoon progression, in this section we turn our attention to the relative humidity values of the air masses involved, to investigate the possible interaction between moist monsoonal flow and the incursion of dry air. As mentioned in the introduction, Krishnamurti et al. (2010) linked the occurrence of a dry 2009 ISM season with the presence of descending and very dry mid-tropospheric air advected towards central India from western Asia (see in particular their Figure 5). Parker et al. (2016) have also illustrated its link with the onset progression. They showed that this wedge-shaped dry-air incursion from the northwest overruns the moist low-level monsoonal air flowing from the southwest, which gradually erodes it from below enabling monsoon-associated deep convection to advance towards northwestern India (see in particular their Figure 13). The evolution of these two different air masses is shown in Figure 7, displaying relative humidity at 760 hPa every 5 days between 10 and 25 June, at 06 UTC. This pressure level has been chosen as the best compromise to capture both the moist monsoon flow, whose core is at low-levels, and the mid-level dry-air incursion.

Figure 7, referring to 10 June, shows the clear and well-defined boundary between dry and moist air masses, located over a line that crosses the Arabian Sea going from the Aden Gulf to northwestern India. While weak westerlies transport moist air over the the southern part of the Arabian Sea towards southern India, weak northwesterlies over the Persian Gulf move dry air towards the northern stretch over the Arabian Sea and the humidity front. Figure $7 \mathrm{~b}$ highlights the equatorward progression of the dry air by 15 June, supported by stronger northwesterly winds, with low relative humidity values now covering over most of the Arabian Sea, even towards southern India. It is important to note that this situation is associated with the strengthening of the northerly flow from higher latitudes behind the

This article is protected by copyright. All rights reserved. 

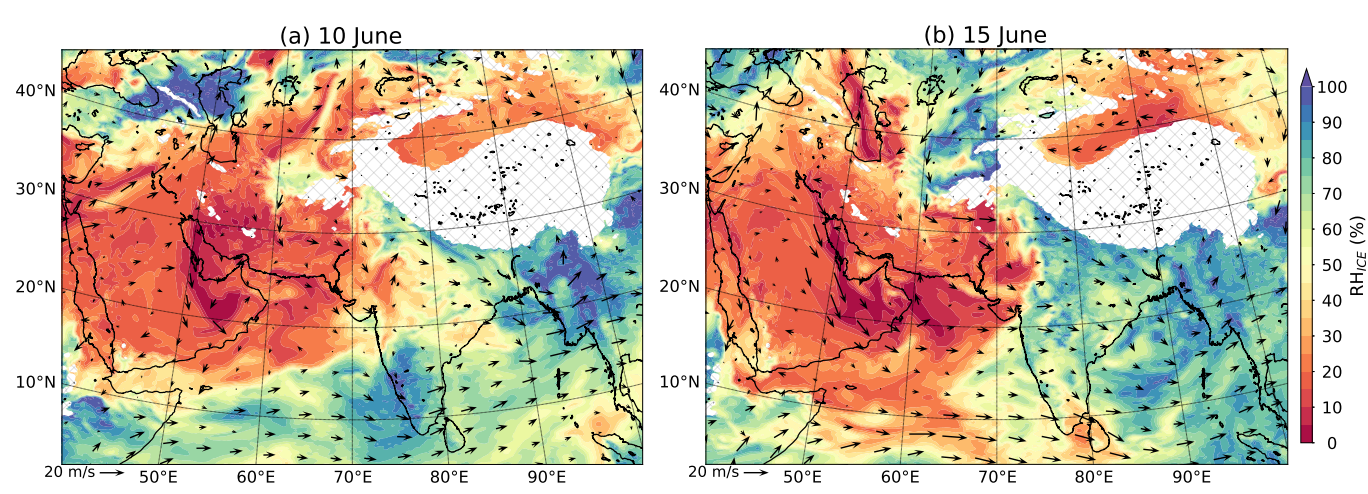

\section{(c) 20 June}
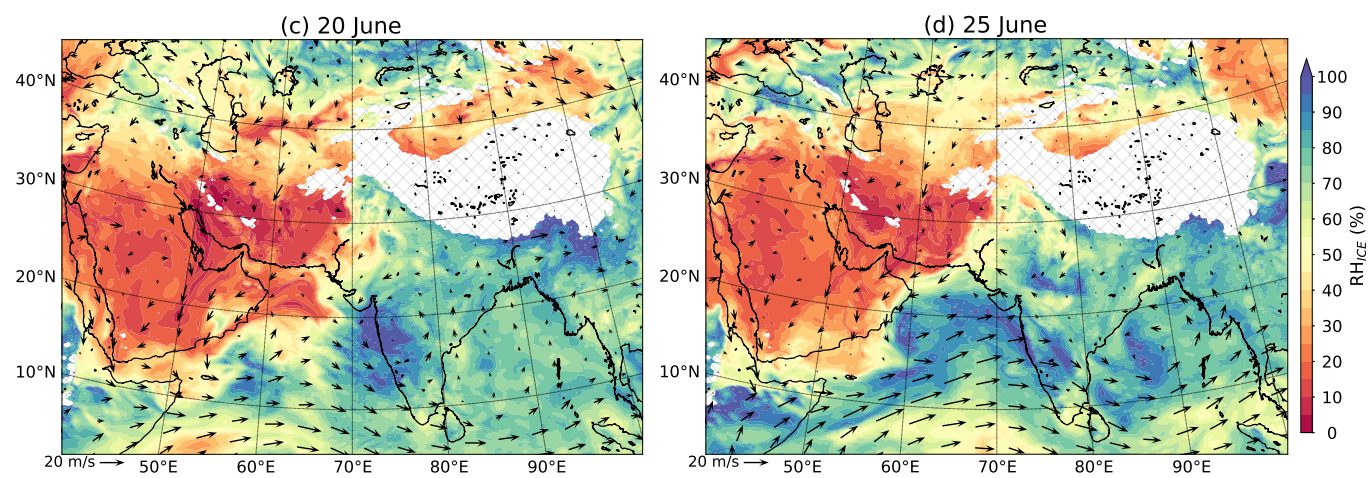

FIG URE 7 Relative humidity with respect to ice (shading, \%) and horizontal wind vectors (quivers, $\mathrm{m} \mathrm{s}^{-1}$ ) at $760 \mathrm{hPa}$ at 06

UTC on (a) 10 June, (b) 15 June, (c) 20 June, (d) 25 June 2016. Data from global MetUM operational forecasts initialised at 00

UTC on the same day as which each panel is labelled (Section 2.1).

13

trough passing over central Asia and the formation of the cyclonic system described in previous sections.

Dry air continues to retreat back towards western Asia on 25 June (Figure 7d), with moist flow now covering almost

(1)

entirely the Arabian Sea, encircling the cyclonic system and carrying almost-saturated air from East Africa to southern and central India and the Bay of Bengal.

In summary, looking only at the first and last panels of Figure 7, as with Figure 5, a gradual northward progression and deepening of the moist monsoon flow could be inferred. However, analysis of the intervening period highlights how this process is far from linear. These panels also confirm that the competition between dry and moist air masses is markedly affected by the occurrence of synoptic-scale features, such as the cyclonic circulation in the Arabian Sea, in turn influenced by the large-scale dynamics at higher latitudes (e.g. the passage of a trough on the subtropical jet with its associated northerly flow).

\section{4 | Large-scale Lagrangian trajectories}

As outlined in Sections 1 and 2.4, Lagrangian methods, such as backward and forward trajectories, can be useful for investigating the evolution of airstreams, their source regions, and processes modifying physical quantities along those flows. Lagrangian trajectories are used in Krishnamurti et al. (2010) to highlight the different pathways of air arriving over northern India. Computing backward trajectories from starting points at $700 \mathrm{hPa}$ and $850 \mathrm{hPa}$, they show that only

This article is protected by copyright. All rights reserved. 
of the lower troposphere. The equivalent procedure is then followed to identify the core of the dry flow (now looking for the lowest relative humidity values). Hence, 400 points are selected in total for each date and trajectories are run backward for 120 hours and forward for 54 hours from these starting points. The results of this computation are shown in Figure 8, where only 10 trajectories for each core (i.e. 5 for each layer) are represented for clarity. In particular, the trajectories displayed are the 5th, 25th, 50th, 75th and 95th quantiles of each set of 100 trajectories, sorted by the latitude of their starting points, in order to capture the latitudinal spread of the airstreams.

Figure 8a, referring to starting points identified on 10 June at 06 UTC, shows westerly and northwesterly dry flow towards the Pakistan-India region from western and central Asia. This air is generally descending from higher altitudes and its low-level path is influenced by the orography, in particular the Hindukush range. Air descending over the northern Arabian Sea from mid-levels experiences subsidence associated with anticyclonic circulation. It can be noted that the low-level dry airstream does not propagate beyond Pakistan, with no further advance in the forward trajectories. This difference southward propagation of dry air between low and mid-levels suggests that the dry-air incursion is wedge-shaped, in agreement with the results in Parker et al. (2016). The moist flow displays a classic Somali Jet pattern at low and mid-levels with southwesterly flow from East Africa towards the Arabian Sea and westerly flow towards southern India. Figure $8 \mathrm{~b}$ refers to trajectories starting on $15 \mathrm{June}$, when the equatorward extension of the dry-air incursion is at its maximum, as shown in previous figures. Lagrangian trajectories are consistent with these findings, since they show that dry air crosses the northern stretch of the Arabian Sea zonally after passing over the Persian Gulf, rather than coming from inland through northwesterly flow. There is still some low-level northerly flow coming from central Asia, associated with the mid-latitude trough. The strengthened dry westerlies over the Arabian Sea are associated with an increased advection of dry air over the Indo-Gangetic plains, this time both at low and mid-levels. However, at the same time the core of the moist airstream also propagates over northern India, where the interaction between these two very different air masses must then be taking place.

Figure $8 \mathrm{c}$ shows the paths of trajectories starting on 20 June, when a well-developed cyclonic circulation is present over the Arabian Sea, just off the Oman coast. The core of the moist airstream flows on its southern side over the northern Arabian Sea, preventing dry air from accessing that region. The dry air masses have indeed substantially retreated and, after flowing meridionally at low-levels from central Asia or more zonally at higher levels from western Asia, fail to propagate southward beyond Pakistan. In general, both moist and dry airstreams struggle to propagate zonally over India as the limited length of forward trajectories shows, in agreement with our previous findings in the Eulerian analysis. It is important to note that the moist core also contains trajectories flowing southeastwards over the Arabian peninsula, associated with the passage of the trough already described in this large-scale analysis. The last panel (25 June, Figure 8d) shows a situation where the two air masses are well-separated. Dry air flows mainly southward from central Asia and fails to reach beyond the Hindukush range, not even as far as the Indus valley in Pakistan. Conversely, the moist flow is now well-established over India and the C-shaped path from Somalia towards India can be clearly seen, along with the development of the cyclonic flow over the Bay of Bengal as the formation of a monsoon depression there is imminent. This moist flow is now very coherent and regular, with all selected trajectories following a similar path, indicating that this is the evolution of a single air mass. It is also important to note that the cores of the two different air masses are separated by more than $10^{\circ}$ in latitude. From the lack of propagation of the dry air and the results of previous sections, we can infer that at this time (25 June) the moist air is covering most of the inland areas south of the Himalaya - Karakoram ranges, while its core flows over southern India. This proves the greatly increased extension of the moistened region, where the ISM is already active, and contrasts markedly with previous panels, in which the cores of different air masses are interacting closely.

This article is protected by copyright. All rights reserved. 


\section{5 | Summary of large-scale analysis}

The analysis of the large-scale situation associated with the June 2016 ISM progression has been carried out using global operational MetUM forecast data. This analysis shows that the progression of the ISM toward northwestern India is a non-steady process, far from gradual and linear and containing "hiatus" and "advance" stages (terminology by IMD). This progression consists of a shift in the balance between the moist southwesterly monsoonal flow and the northwesterly incursion of dry air, linked to and influenced by the occurrence of transient synoptic-scale features in the region, e.g. cyclonic circulations. These weather features are in turn embedded in the large-scale circulation and connected with synoptic-scale dynamics at higher latitudes, as stressed by the analysis of PV. During this process, the cores of dry and moist air masses can interact very closely, shaping the onset and progression of the monsoon. A more detailed analysis of the dynamics of this interaction is thus necessary. This analysis is presented in Section 5.

\section{5 | RESULTS: REGIONAL ANALYSIS}

$\overbrace{-1}$

This section contains the analysis of the $4.4 \mathrm{~km}$-resolution LAM simulation. After having analysed the large-scale dynamics of 2016 ISM progression, we now use the output of high-resolution convection-permitting simulations to focus on northwestern India and investigate in greater detail and at smaller scales the evolution of the sharp boundary between dry and moist air masses. Furthermore, with high-resolution data, more accurate trajectories can be computed in order to reveal the mesoscale path of the different airstreams and assess the effect of diabatic processes along them. An Eulerian analysis is presented in Section 5.1, while the analysis of Lagrangian trajectories is the content of Section 5.2

\section{1 | Regional Eulerian analysis}

In this section, maps, cross sections and thermodynamic profiles are used to characterise ISM progression in June 2016 over northwest India, i.e. where moist and dry air masses interact more closely. A detailed picture of the tropospheric evolution during monsoon progression can thus be produced. The description will then be completed by the Lagrangian analysis in Section 5.2, focused on the evolution of the airstreams involved and the associated diabatic processes.

\section{June: Initial situation}

Figure 9 contains an overview of the tropospheric situation over northwestern India on 10 June 2016. Relative humidity is used to highlight dry and moist air masses. Figure 9 a highlights the presence of a dry-air incursion from the northwest in the mid-levels, affecting mainly Pakistan and northwest India. The mid-troposphere is moister towards the southeast, with irregular moist patches possibly indicating the occurrence of convection at the boundary with the dry air and over the Gangetic plain. Figure 9b shows instead that at low levels there is southwesterly flow over the Arabian Sea, associated with the advection of nearly-saturated air towards the coasts of India and Pakistan and the occurrence of single-cell convection off-shore. This moist advection does not penetrate inland, where the low levels are substantially drier.

Cross section AB, shown in Figure 9c, goes from the Arabian Sea to the Himalayan foothills, crossing the Thar desert and the northern Indian plains. The use of cross sections allows us to investigate the vertical composition of the air masses identified in the maps. This section highlights the sharpness of the boundary between the low-level southwesterly flow and the overrunning northwesterly dry-air incursion. Being the cross section orientated from southwest to northeast, it highlights the southwesterly moist flow through the transect-parallel component of the wind vectors. A two-layer situation is visible in the bottom-left corner of the section, i.e. over the Arabian Sea and the coasts

This article is protected by copyright. All rights reserved. 

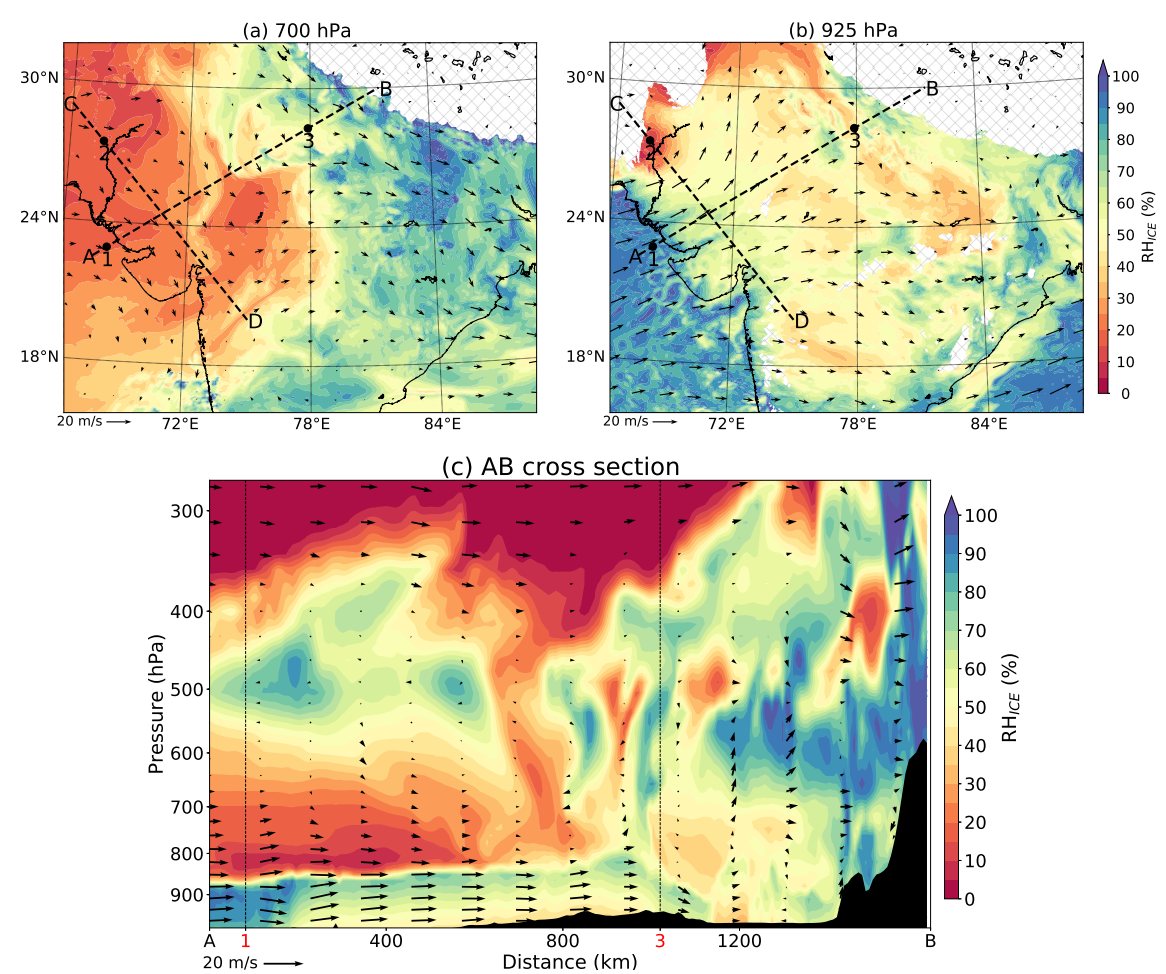

(d) CD cross section

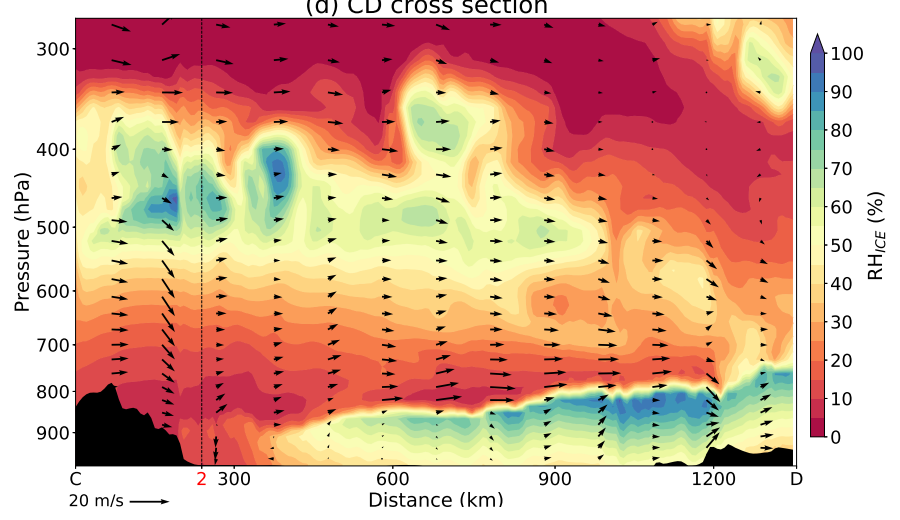

F I G URE 9 (a),(b): Maps of relative humidity with respect to ice (shading, \%) and horizontal wind vectors at (a) $700 \mathrm{hPa}$ and (b) $925 \mathrm{hPa}$ at 06 UTC on 10 June 2016. Dashed lines indicate the location of cross sections transects and numbered dots indicate the locations of thermodynamic profiles to be used later in Figures 10 and 14. (c),(d): cross sections over transects (c) $A B$ and (d) CD. Quivers in (c) and (d) are constructed using the wind parallel to the cross-section as horizontal component and vertical velocity multiplied by 40 as vertical component. Data from LAM simulation (Section 2.2).

of Gujarat, with the boundary located at around $880-850 \mathrm{hPa}$. The dry-air incursion sits between 850 and $600 \mathrm{hPa}$, with its core at around $800 \mathrm{hPa}$, while the moist layer flows underneath. The cross section confirms that the low-level 
Location 1 - 06 UTC 10 June

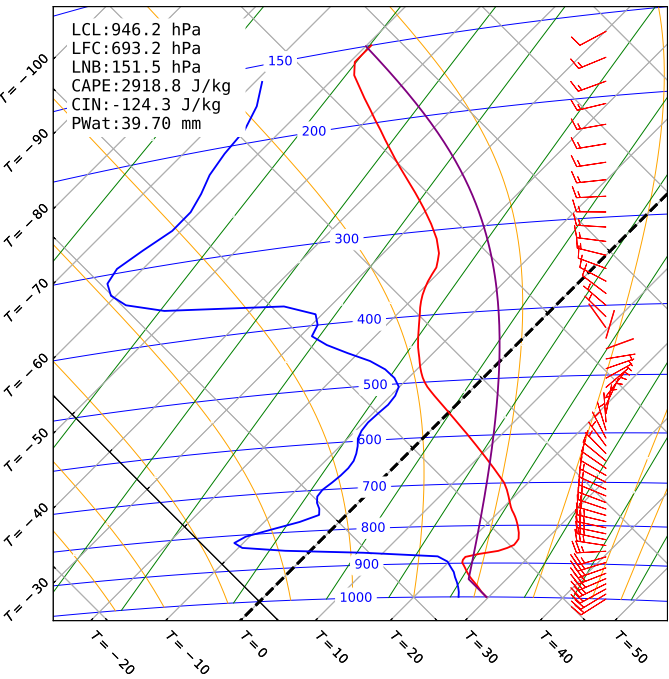

Location 2 - 06 UTC 10 June

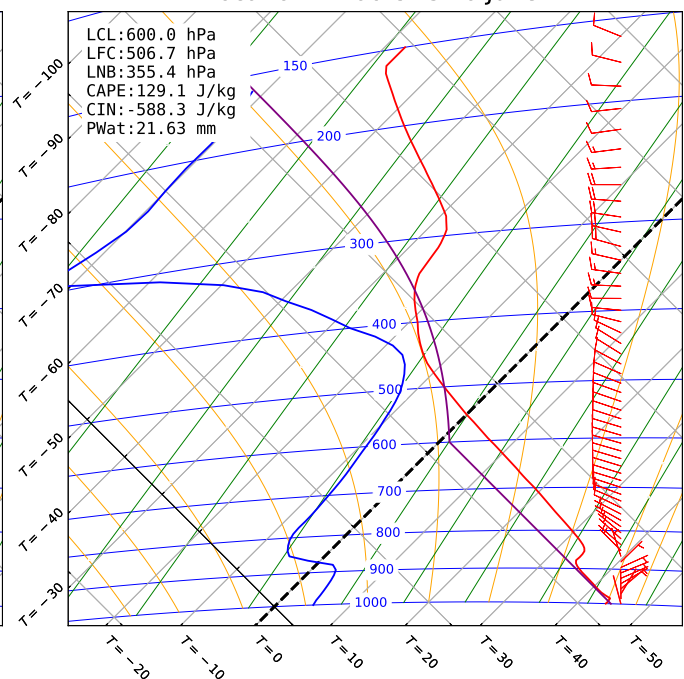

F IG URE 10 Thermodynamic profiles (tephigrams) computed at indicated locations at 06 UTC on 10 June 2016. Solid lines indicate environmental dry-bulb temperature (red), environmental dew-point temperature (blue) and ascending-parcel temperature (magenta). Thermodynamic indices in the top-left box are computed using virtual temperatures. Isolines included in the profiles are isotherms (grey upper right - lower left lines, solid black for $\mathrm{T}=0^{\circ} \mathrm{C}$ ), dry adiabats (grey upper left - lower right lines, solid black for $\theta=0^{\circ} \mathrm{C}$ ), wet adiabats (yellow lines) and constant mixing ratio lines (green lines). Red barbs indicate wind direction (upward-pointing for southerly wind) and strength (full feather $=5 \mathrm{~m} \mathrm{~s}^{-1}$, half feather $=2.5 \mathrm{~m} \mathrm{~s}^{-1}$ ). Data from LAM simulation (Section 2.2).

almost-saturated air does not penetrate inland, where the air immediately above the surface is not close to saturation (although the panels refer to around 12pm local time, so a drying effect caused by sensible heating is to be expected).

Cross section $C D$ (Figure 9d), which is roughly perpendicular to $A B$ and goes from the Hindukush range to central India through the Indus valley and Gujarat, is instead aligned with the northwesterly dry-air incursion. This dry-air incursion extends all the way down to the surface in the northwestern corner of the section, over a region on the lee side of the Hindukush range that is more sheltered from the moist advection. In contrast, in the central part of the section the two-layer pattern is clearly visible, with the moist advection undercutting the dry-air incursion. It is also worth noting that close to the tropopause the circulation is still dominated by westerlies, indicating that the upper-level easterlies associated with the mature ISM have not yet developed.

In addition to maps and cross sections, thermodynamic profiles are also included in order to characterise the vertical profile of the troposphere and its stability. Profile 1 (Figure 10a) is evaluated just off-shore of Gujarat and contains both the dry-air incursion, centred at around $800 \mathrm{hPa}$, and the moist flow underneath. Wind barbs show the sharp transition between moderate southwesterly moist flow and west-northwesterly dry flow just above $900 \mathrm{hPa}$. The profile shows that the presence of dry air is instrumental for the inhibition of deep convection, which would otherwise occur owing to the large CAPE shown by the parcel ascent. The moist low-level flow under $900 \mathrm{hPa}$ is associated with a well-mixed layer and southwesterlies almost constant with height. This confirms the possible occurrence of shallow single-cell convection, failing to evolve in deep convection because of the non-negligible CIN associated with the dry layer. Profile 2 (Figure 10b) samples an area in the Indus Valley, just on the lee side (for zonal flows) of the southern foothills of the 
Hindukush range. Here all the lower troposphere is markedly dry, particularly towards the surface and at $800 \mathrm{hPa}$. Winds are weak and of variable directions at low levels. Although the lower half of the profile is stable, some CAPE is present at mid-levels. In fact, in both tephigrams the mid-levels are not particularly stable or dry (consistent with relatively moist areas around $500 \mathrm{hPa}$ and higher vertical wind speeds locally visible in Figures $9 \mathrm{c}$ and $9 \mathrm{~d}$ ). This could be due to prior occurrence of deep convection.

\section{5 - 20 - 25 June: Subsequent evolution}

15 June The maps and cross sections in Figure 11 show a similar situation to that on 10 June (Figure 9). However, there are also some notable differences. In fact, Figure 11a displays a slightly larger horizontal extension of the dry-air incursion at $700 \mathrm{hPa}$ (consistent with the global analysis), while Figure $11 \mathrm{~b}$ shows that at the same time the southwesterly flow penetrates further inland, up to the Karakoram foothills, removing the very dry air from low-levels. This result confirms the hypothesis arising from Figure 8, namely that the cores of both air masses get closer to each other around 15 June, with northwest India being where the interaction between these airstreams takes place.

Marked drying occurs at mid levels, particularly evident at around $500-600 \mathrm{hPa}$, and is displayed by both cross sections (Figures 11c and 11d). These cross sections also show that the sharp boundary between the moist low-level flow and the dry air above rises slightly, now up to $800 \mathrm{hPa}$ over central India. The wind speed vectors in Figure 11d highlight the primary role of the dry incursion in preventing the occurrence of deep convection, with shallow updraughts over northwest India being capped by the dry and stable air above. Deep convection is instead locally triggered on the lee side of the Hindukush, where orography can overcome the stabilising effect of the dry incursion, confirming the relatively low static stability of the middle troposphere above the dry-air incursion core.

In summary, while the low-level southwesterly flow advances slightly inland and grows in height, the dry incursion does the same above, continuing to prevent the triggering of deep convection. In other words, the low-level moist flow is deeper but above it the mid-troposphere is generally drier, and contrasts in the area are becoming more obvious. This is far from the simple idea of a smooth monsoon progression with the moist flow steadily advancing while the dry-air incursion gradually retreats.

20.June The maps in Figures 12a and 12b depict a situation distinctly different from before, with the low-level moist flow failing to reach northwestern India while an anticyclonic circulation is present over land, driving dry air southward. The two-layer pattern is no longer visible. This situation is associated with the presence of the aforementioned cyclonic circulation in the Arabian Sea and the absence of westerlies towards the Indian subcontinent. The very sharp boundary between dry and moist air visible at $700 \mathrm{hPa}$ is probably associated with this cyclonic circulation, triggering northerly dry winds on its western side.

Cross section $A B$ (Figure 12c) shows that in fact the two-layer pattern is still present, but only over the sea. The northwesterly dry-air incursion is now markedly wedge-shaped and very thin at its eastern end. The undercutting southwesterly flow is only visible off-shore. The dry-air incursion at low levels caused by inland northerly winds is visible

in the central portion of this cross section. This airstream contains dry air from the surface upwards, in contrast to the northwesterly dry-air incursion which is usually overrunning a moist layer. This cross section also hints at a reduction of the amount of dry air in the mid-troposphere. Cross section CD (Figure 12d) confirms this result by clearly showing that a southeasterly mid-level flow pushes the dry air back towards northwest India. Hence, while the southwesterly moist advection is prevented by the synoptic-scale circulation, the same circulation enables moist air to advance at mid-levels.

25 June Figures 13a and 13b show a well-developed monsoon over the area. An active low-level southwesterly moist flow is visible, pushing the remaining dry air close to the Himalayan foothills. The lower troposphere is now generally

This article is protected by copyright. All rights reserved. 

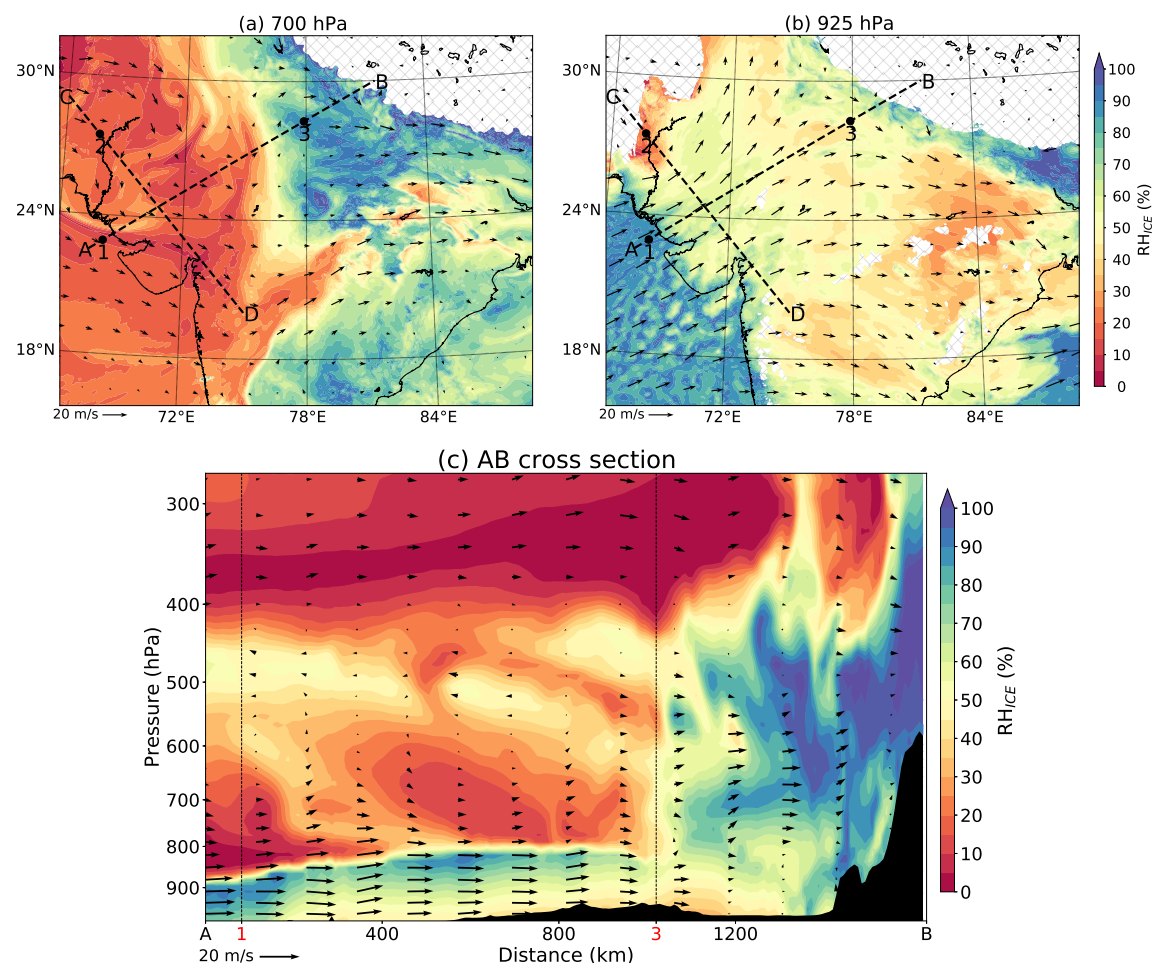

(d) CD cross section

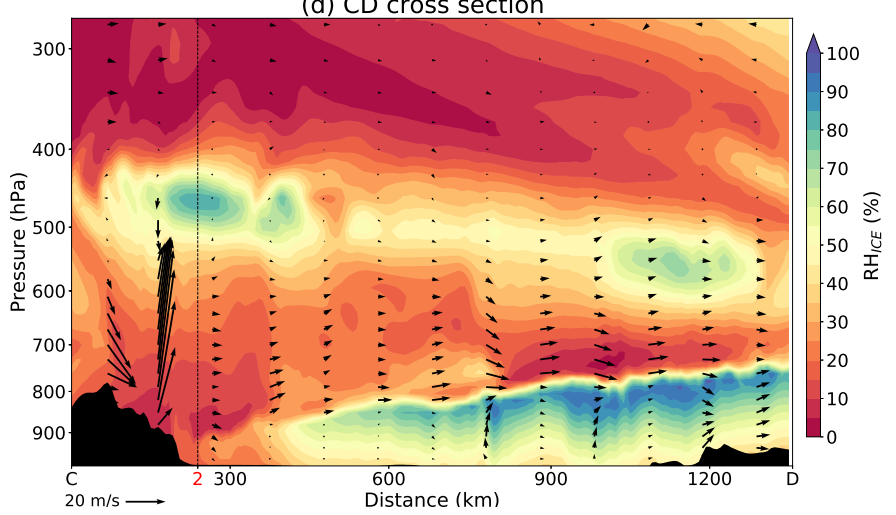

F I G URE 11 Same as Figure 9 but at 06 UTC on 15 June 2016. Data from LAM simulation (Section 2.2).

moist, with irregular structures in relative humidity hinting at the occurrence of multi-cell convection and associated convergence zones. Light winds and moist air dominate the situation at $700 \mathrm{hPa}$, with a weakening anticyclonic circulation between northern India and Pakistan. The two cross sections (Figures 13c and 13d) show that the moist southwesterly flow is now deeper, extending above the $800 \mathrm{hPa}$ level. The dry-air incursion has been substantially eroded and moderately dry air is now only present close to the Himalaya and Hindukush ranges. Remarkably, above the moist southwesterly flow, an easterly jet dominates the flow in the mid- and upper troposphere, showing a marked 

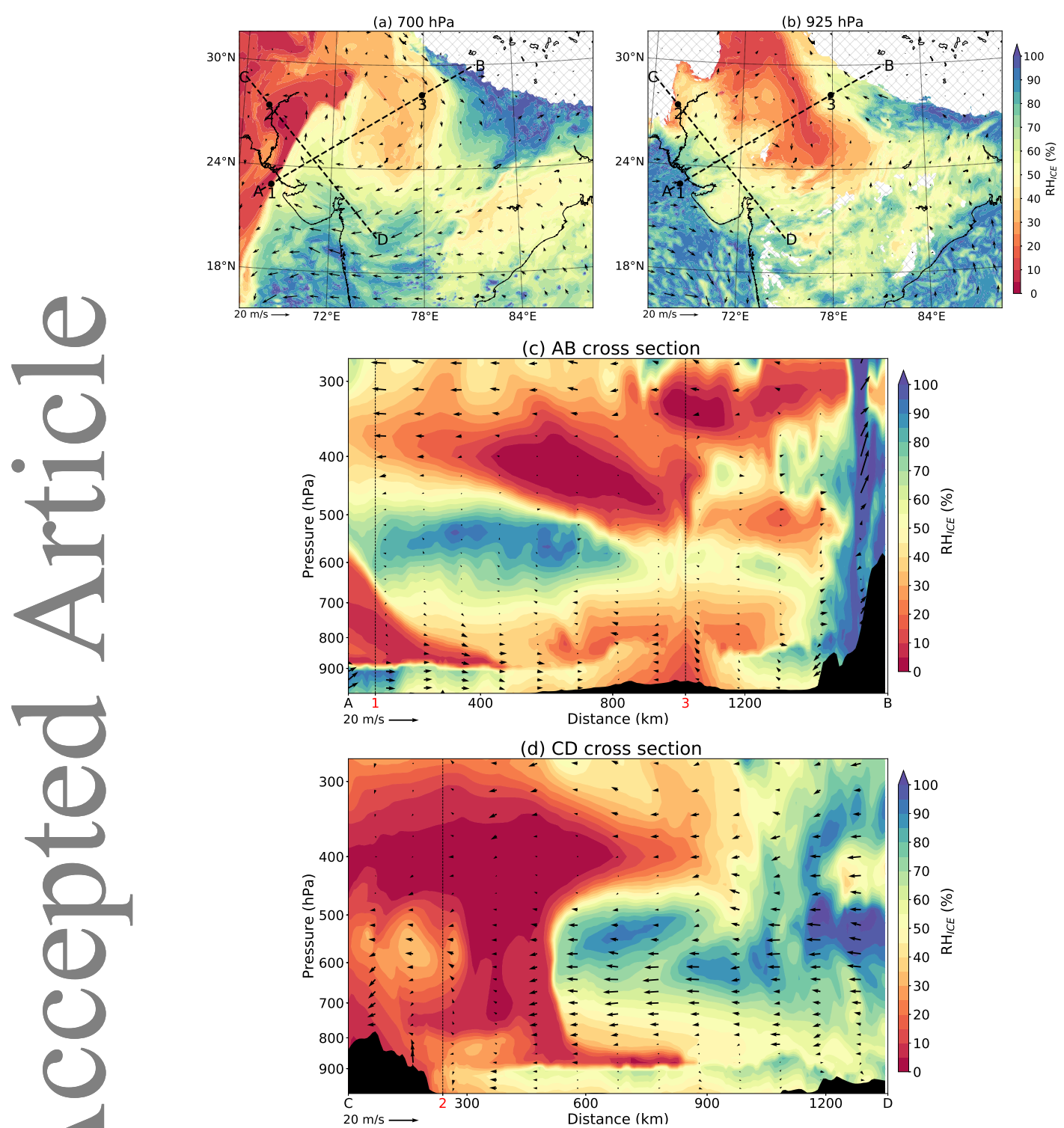

F I G URE 12 Same as Figure 9 but at 06 UTC on 20 June 2016. Data from LAM simulation (Section 2.2).

advancement towards a mature monsoon state.

Thermodynamic profiles Additional thermodynamic profiles are provided here, to complement the LAM Eulerian analysis of the 2016 ISM progression. These profiles are computed at location 1 on all dates, so that they can be compared with Figure 10a (referring to 10 June), and at location 3 on 20 June, to highlight the characteristics of the dry-air incursion caused by inland low-level northerlies.

This article is protected by copyright. All rights reserved. 

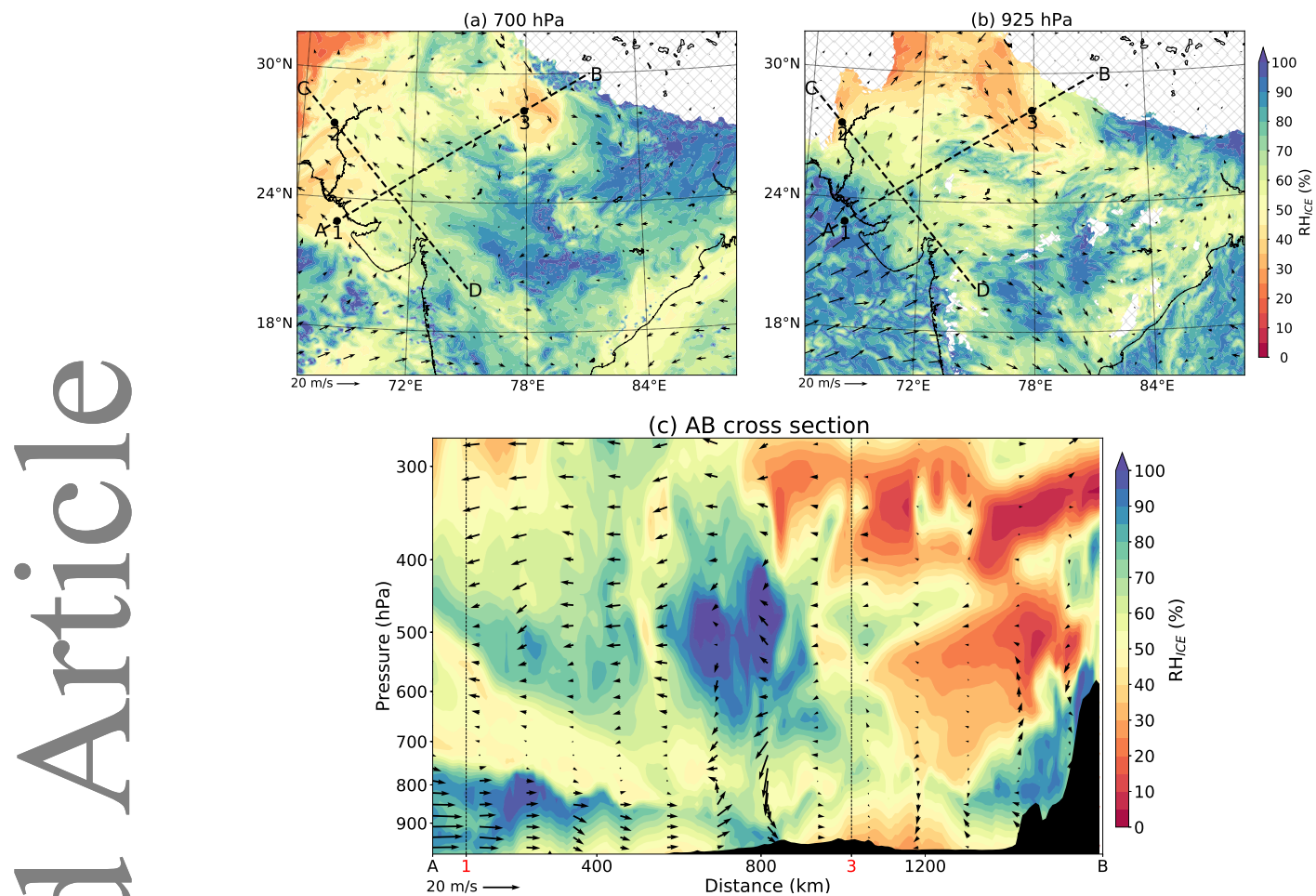

(d) CD cross section

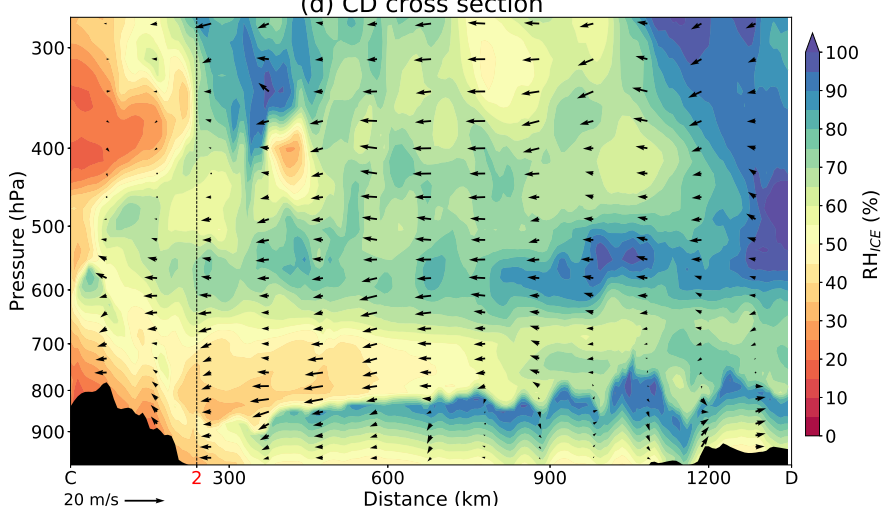

F I G URE 13 Same as Figure 9 but at 06 UTC on 25 June 2016. Data from LAM simulation (Section 2.2).

Figure 14a shows that Profile 1 on 15 June is similar to its equivalent computed on 10 June. The two-layer structure is evident, with west-northwesterly dry air overrunning southwesterly moist flow and the associated well-mixed boundary layer. The core of the incursion, drier than in Figure 10a, is just below $800 \mathrm{hPa}$, with sharper gradients between different air masses. The presence of the dry incursion is still responsible for the inhibition of deep convection. Figure 14b instead displays a different situation since on 20 June Profile 1 contains zonal moist flow only below 900 $\mathrm{hPa}$, with even the dry incursion being confined to lower levels. The dry air is also associated with very weak horizontal 
Location 1 - 06 UTC 15 June

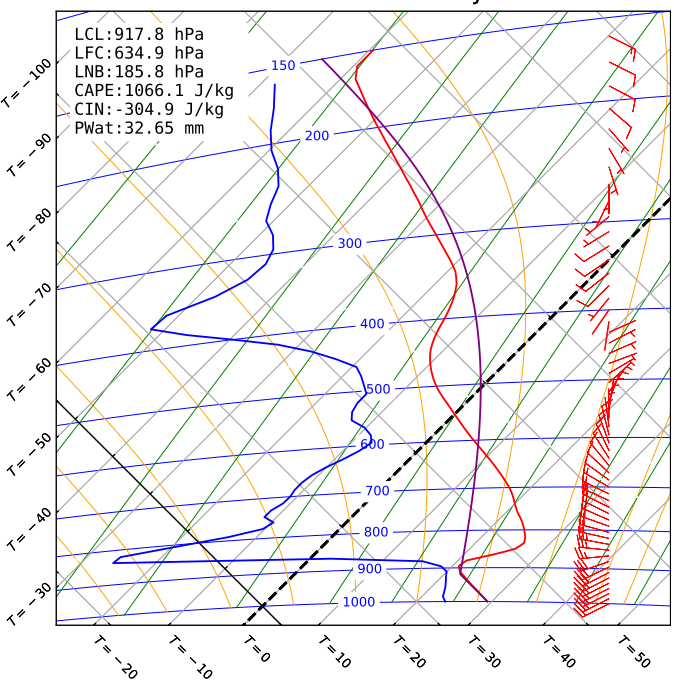

Location 1 - 06 UTC 25 June

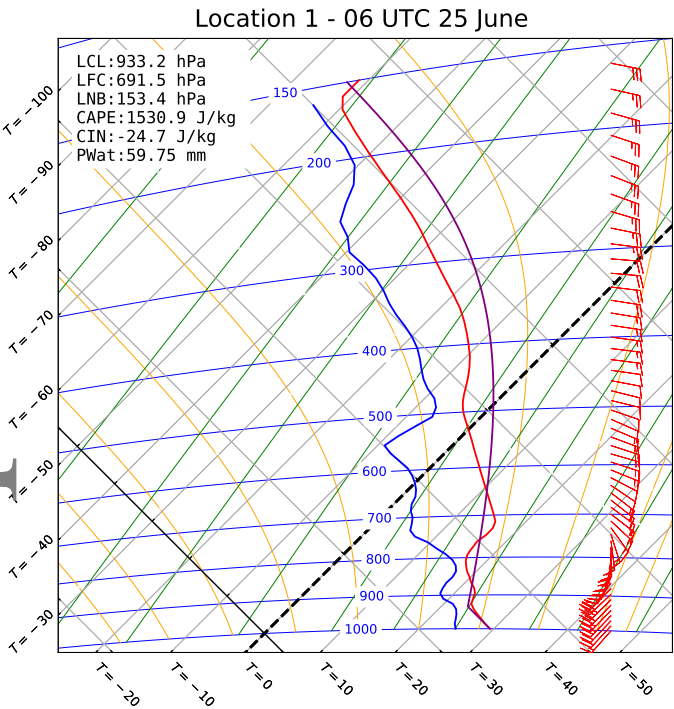

Location 1 - 06 UTC 20 June

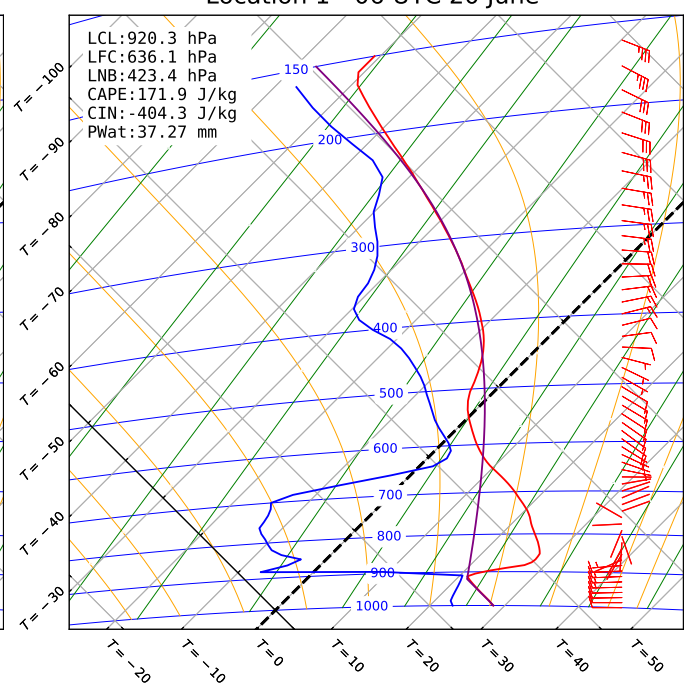

Location 3 - 06 UTC 20 June

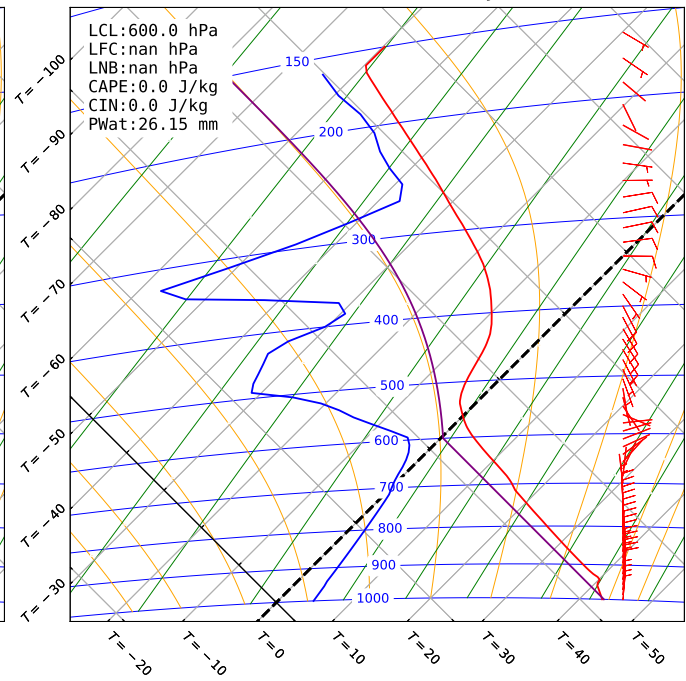

FIG URE 14 Same as Figure 10 but at indicated locations at 06 UTC on 15, 20 and 25 June 2016. Data from LAM simulation (Section 2.2).

winds and local subsidence rather than being advected from elsewhere. The troposphere is instead moist above $700 \mathrm{hPa}$, consistent with the southeasterly moist advection outlined in the cross sections (Figure 12). The profile is conditionally unstable, with deep convection still being prevented by $\mathrm{CIN}$ associated with the dry-air incursion. On 25 June (Figure 14c) the dry layer at low-mid levels is no longer evident and Profile 1 is now favourable for deep convection, with large CAPE and no CIN. Coherent and sustained southwesterly flow is present below $850 \mathrm{hPa}$, quickly turning to southeasterly and then easterly from mid levels upwards. The profile is moist throughout the whole troposphere but

This article is protected by copyright. All rights reserved. 
never saturated, with only small dry remnants between $700 \mathrm{hPa}$ and $500 \mathrm{hPa}$.

Figure 14d shows Profile 3 on 20 June, computed over the northern Indian plains in order to highlight the characteristics of the northerly inland dry incursion. This profile shows that the core of the dry layer, extending up to above $700 \mathrm{hPa}$, is at the surface. Weak northerly winds advect the dry air towards the plains of northern India. The lapse rate is close to a dry adiabat, possibly indicative of an earlier dry descent. However, the profile is stable and CAPE is absent. The profile is moister at $600 \mathrm{hPa}$, where the weak winds suddenly rotate to southerlies, gradually backing to easterlies at high levels.

\subsection{1 | Summary of regional Eulerian analysis}

The Eulerian analysis of the high-resolution LAM simulation confirms that a two-layer pattern, southwesterly low-level moist flow overrun by a northwesterly dry-air incursion, is present over northwest India during monsoon progression. The sharp boundary between these two air masses converging into the region is located at around $800-850 \mathrm{hPa}$. The dry-air incursion is essential in preventing the triggering of deep convection, while shallow convection occurs in the lowlevels, consistent with Parker et al. (2016). It is only when the dry layer is removed and the monsoon is well-developed that deep convection is free to occur. This regional analysis confirms that monsoon progression is far from being a smooth process, as shown by the irregular variations in extension, direction and strength of the two air masses at play. These variations are linked with the regional circulation, in turn associated with the behaviour of the upper-level subtropical jet analysed in Section 4.

\section{2 | Regional Lagrangian analysis}

\subsection{1 | Paths of dry and moist air masses}

As explained in Section 4.4, Lagrangian trajectories are a useful method of analysis when investigating the dynamics of air masses. This of course also applies when using high-resolution regional models, as these data can enable a close look at the path of different air masses, revealing local effects and diabatic processes. The domain chosen for the selection of starting points is much smaller in this case than the one used in Section 4.4 as the analysis is focused on

the interaction between air parcels that belong to the two different layers meeting over northwestern India. For this reason, the starting points are selected within $66.5^{\circ} \mathrm{E}-69^{\circ} \mathrm{E}$ and $22^{\circ} \mathrm{N}-24^{\circ} \mathrm{N}$. The 100 grid points with highest and lowest relative humidity located between $1000 \mathrm{hPa}$ and $700 \mathrm{hPa}$ constitute the core of the interacting part of the moist low-level flow and of the dry-air incursion, respectively. From these points, trajectories are run backward for 42 hours and forward for 30 hours. The results of the computation are shown in Figure 15 and, unlike Figure 8, all trajectories are included.

Figure 15a refers to starting points identified on 10 June. The trajectories constituting the moist flow cross the Arabian Sea as low-level southwesterlies. While most of them appear to be flowing from equatorial oceanic regions, a few come from the southern tip of the Arabian Peninsula. Dry trajectories flow instead over the Persian Gulf before crossing the Arabian Sea, following a slightly northern path with respect to the moist ones. Both airstreams then move inland, with the dry layer overrunning the moist one. Figure 15b show that a similar situation occurs on 15 June, with the following differences. A substantial minority of the moist trajectories flow over the southern Arabian Peninsula from the northwest before turning cyclonically and joining the rest of the airstream as southwesterly flow over the Arabian Sea. This is consistent with the aforementioned early development of a cyclonic circulation in the area at that time, associated with the passage of a trough at higher latitudes and the strengthening of northwesterly flow over the

This article is protected by copyright. All rights reserved. 
(a) 10 June

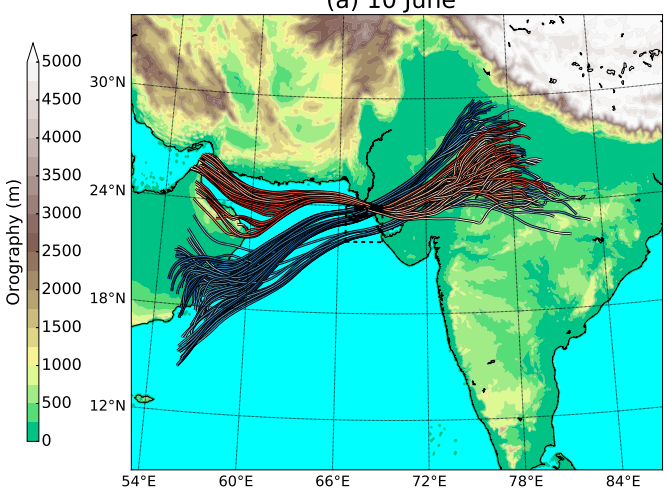

(c) 20 June

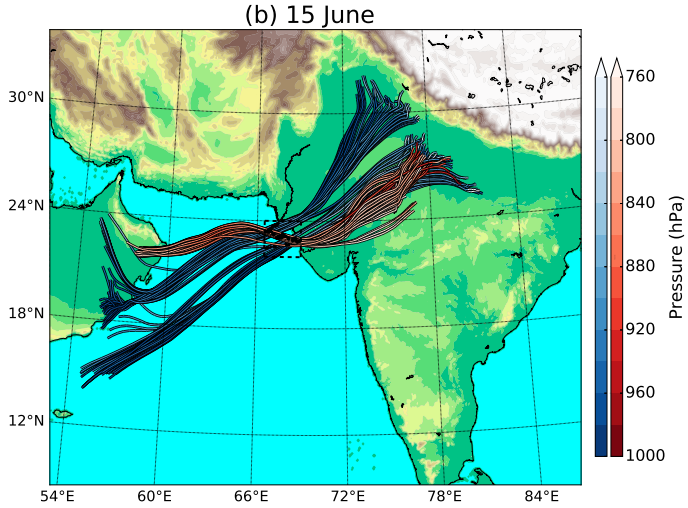

(d) 25 June
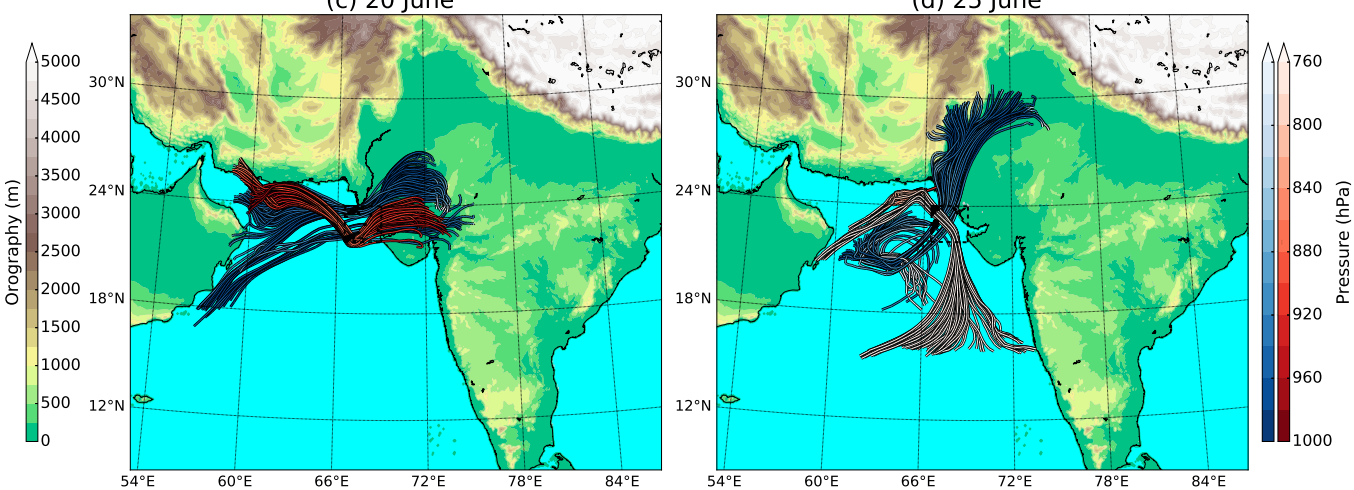

(1)

FIG URE 15 Moist (blue) and dry (red) Lagrangian trajectories starting at 06 UTC on (a) 10 June, (b) 15 June, (c) 20 June, (d) 25 June 2016, computed backward for 42 hours and forward for 30 hours. Dashed black lines define the selection domain (see

text in Section 5.2.1 for more details on the selection process). Colour shading indicates the pressure height of trajectories at cay position and black dots within the small domain indicate the starting points of the selected trajectories. Data from LAM

simulation (Section 2.2).

(1)

(Section 2.2).

Persian Gulf. Inland propagation of both airstreams is now oriented towards the northeast, more meridional than on 10

June, with moist trajectories in particular reaching the Himalayan foothills.

Figure $15 \mathrm{c}$ refers to 20 June and also in this case shows more substantial differences than previously. The trajectories are roughly half in length compared to previous panels, indicating weaker winds and less space covered by the airstreams. This is a consequence of the already-described absence of zonal circulation in the area. The moist airstream shows again a dual origin, over the Arabian Sea or the tip of the Persian Gulf, whereas the dry airstream flows west-northwesterly over the Persian Gulf. The inland propagation of both airstreams is greatly reduced. It should be noted that the height at which the dry air flows is much lower and closer to the moist flow than in previous panels (see colour shading), possibly a consequence of the subsiding anticyclonic environment in which the airstreams enter. Figure 15d shows that on 25 June the moist flow is much deeper and forces the dry air to flow at higher levels. The circulation in the area is dominated by cyclonic motions that are evident in the path of both airstreams. The moist flow this time propagates easily northwards inland along the Indus Valley.

This article is protected by copyright. All rights reserved. 
In summary, this figure shows that dry and moist flow travel on similar paths for a significant amount of time in this two-layer pattern over the Arabian Sea and northwest India. The figure confirms how the motion of these trajectories is substantially affected by the occurrence of weather systems in the area that shape the interaction between dry and moist air and the inland progression of the monsoon. Since these panels have highlighted that air with different origins can travel together in these airstreams, the next section will investigate which processes act on the trajectories during their evolution.

\subsection{2 | Trajectory profiles}

Analysis of the evolution of relevant physical quantities and of associated conservation properties can give insights on the processes at play during the evolution of Lagrangian trajectories, as shown by Volonté et al. (2018) (see their Figure 6) when investigating the mesoscale dynamics of sting jets in extratropical cyclones. Here this analysis is applied to the trajectories shown in Figure 15.

\section{June: Initial situation}

The pressure profile (Figure 16a) shows the gradual descent of the dry-air incursion from mid levels while flowing over the Persian Gulf and the Arabian Sea. More than half of the trajectories belonging to the moist airstream experience a descent of more than $100 \mathrm{hPa}$ at the same stage. This profile, along with that for specific humidity in Figure 16b, highlights the importance of the Arabian Sea in providing moisture to the low-level monsoon flow. Indeed, the majority of these trajectories go through an increase in relative humidity from less than $30 \%$ to more than $95 \%$ in 24 hours while flowing over the sea, when their moisture content increases from $8 \mathrm{~g} \mathrm{~kg}^{-1}$ to $18 \mathrm{~g} \mathrm{~kg}^{-1}$. Those trajectories that are already moist or close to saturation at that stage are the ones that have been previously travelling at low levels. It is only in the boundary layer that the moistening effect of the Arabian Sea is efficient, as the trajectories belonging to the descending dry incursion show. They do not display any non-negligible increase in moisture content, which stays around $2 \mathrm{~g} \mathrm{~kg}^{-1}$ for all the time before the interaction with the low-level airstream.

Potential temperature $(\theta$, Figure $16 \mathrm{c})$ and wet-bulb potential temperature $\left(\theta_{w}\right.$, Figure $\left.16 \mathrm{~d}\right)$ are close to constant for, the dry flow in the whole period before the interaction, suggesting an almost-adiabatic advection and descent of this airstream. The same panels show instead that non-negligible diabatic processes occur on the moist airstream. $A$ decrease in $\theta$ of around $8 \mathrm{~K}$ and an increase in $\theta_{w}$ of around $4 \mathrm{~K}$ take place on at least half of the moist trajectories in less than 24 hours while flowing over the Arabian Sea (the former happens on the already-moist trajectories and the latter on the initially-dry ones). The decrease in $\theta$ for some of the trajectories could be associated with evaporative cooling caused by local precipitation and/or by sea surface evaporation. However, this hypothesis cannot hold for the trajectories already close to saturation. Hence, other processes must be at play. In any case, considering that $\theta_{w}$ is conserved for all moist processes that do not involve ice, it is reasonable to assume that substantial mixing of dry descending trajectories with the moist oceanic boundary layer is taking place.

Another result shown in these panels is the strong mixing occurring over land, as soon as the interaction between the two different air masses takes place. This is highlighted by the sudden increase in specific humidity of the dry incursion (from $2 \mathrm{~g} \mathrm{~kg}^{-1}$ to $13 \mathrm{~g} \mathrm{~kg}^{-1}$ in 6 hours for the median trajectory). This stronger mixing could be favoured by more vigorous boundary-layer convection over land, where sensible heating is likely higher (again, a flux analysis could be beneficial). The discontinuity in boundary layer structure could also be the cause of the sudden ascent of around 50 $\mathrm{hPa}$ in the moist airstream at the same time. A consequence of this strong mixing is that the physical properties of the airstreams converge to intermediate values. From this point, all the trajectories should be considered part of a single broad airstream rather than still belonging to two separate air masses.

This article is protected by copyright. All rights reserved. 
(a) Pressure (hPa)

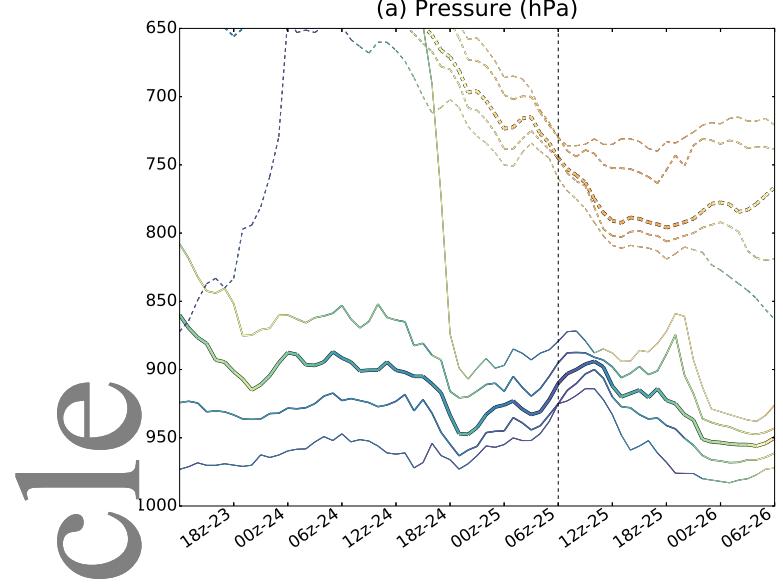

(c) Potential Temperature (K)

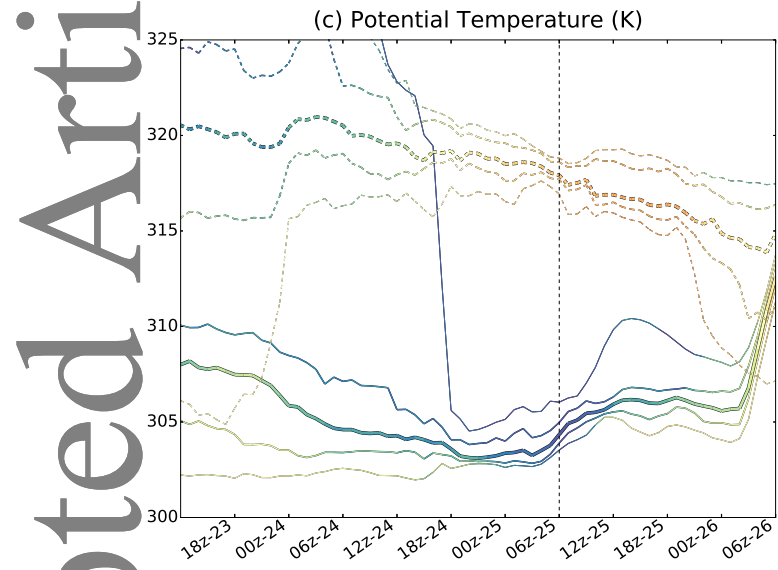

(b) Specific Humidity $\left(\mathrm{g} \mathrm{kg}^{-1}\right)$

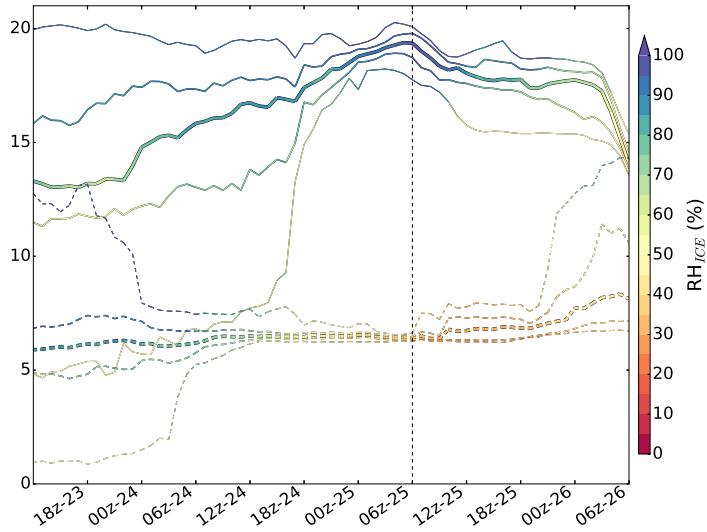

(d) Wet-Bulb Potential Temperature (K)

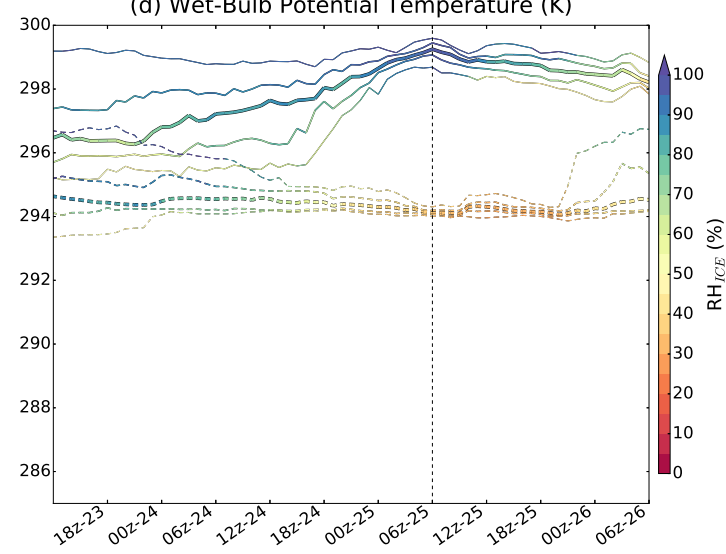

FIGURE 19 Same as Figure 16 but for trajectories starting on 25 June 2016 (see relevant map in Figure 15d). Data from LAM simulation (Section 2.2).

primarily contributing to moisture increase anymore, in clear contrast with the results of previous dates. In fact, most of the trajectories are already close to saturation when over the Arabian Sea. This could be due to an increased residence time of the airstream over the Arabian Sea as a consequence of being embedded in a cyclonic circulation. Alternatively, it could be pointing at the greater importance of remote moisture sources (e.g. equatorial Indian Ocean) in providing moisture to low-level flows when the monsoon is well-developed. A larger domain than available to this study, and trajectories going further back in time, would be required to effectively answer this question.

\subsubsection{Summary of regional Lagrangian analysis}

The Lagrangian analysis of the high-resolution LAM simulation focuses on the cores of the low-level moist flow and descending dry-air incursion, interacting with each other over northwest India. These airstreams follow similar paths, flowing roughly zonally over a northern section of the Arabian Sea. The horizontal and vertical paths of the selected

This article is protected by copyright. All rights reserved. 
trajectories are substantially influenced by synoptic- and meso-scale circulations and even small variations are nonnegligible, given the sharp boundaries between air masses present in the region.

The interaction with the Arabian Sea is of primary importance in providing moisture to air travelling at low levels. In some cases, the majority of the trajectories selected as part of the moist flow pick up most of their moisture content in less than 24 hours while travelling over the Arabian Sea. Moist processes are thus important as, along with mixing, they are able to considerably change the properties of the considered air masses. This interaction has a considerable effect regardless of the strength of the flow. However, when the monsoon evolves towards a mature stage most of the trajectories reaching the northern Arabian Sea are already close to saturation, reducing its importance in providing moisture.

(1)

\section{6 | DISCUSSION AND CONCLUSIONS}

Considerable research on the dynamics of the ISM identifies the low-level southwesterly moist flow from the Arabian Sea and the northwesterly incursion of descending dry air from western and central Asia as two main drivers of its onset and progression. In particular, Parker et al. (2016) explain the role of this dry-air incursion in the northwestward propagation of the monsoon onset by describing a gradual process of moistening from below of this dry wedge-shaped air mass, with the onset occurring when the dry layer is shallow enough to allow deep convection to form. The dynamics of monsoon progression seem to be connected with the large-scale circulation in the extratropics. Vellore et al. (2016) and Martius et al. (2013) give emphasis to the link between mid-latitude troughs and heavy monsoon rainfall. Krishnamurti et al. (2010) focus instead on the relationship between the presence of a blocking high over western Asia and dry-air advection towards India while Fletcher et al. (2018) associate this advection with cyclonic PV anomalies on the subtropical jet over west Asia. Consequently, short-term variability in monsoon progression could be associated with extratropical dynamics, similar to the "bursts" of the Australian monsoon described by Berry and Reeder (2016). It is then crucial to look in detail at how synoptic- and large-scale dynamics can influence the strength of the dry-air incursion and alter its balance with the moist low-level flow associated with monsoon progression.

This analysis has been performed in the present study using data from $17 \mathrm{~km}$ resolution UK Met Office daily global operational forecasts in their first 24 hours from initialisation. High-resolution ( $4.4 \mathrm{~km}$ ) modelling data (from a MetUM

LAM simulation driven at its boundaries by a global MetUM run initialised daily) have also been used in the analysis in order to focus on the detailed evolution of the cores of dry and moist air masses interacting over northwest India during ISM onset and progression. The validity of the conceptual model presented in Parker et al. (2016) has been assessed, with particular attention on whether the ISM progression is a gradual or non-steady process. The effects of local diabatic processes taking place on the relevant airstreams have been investigated with the use of Eulerian and Lagrangian methods, taking into account the interaction with the ocean surface.

Results of this study show that the progression of the ISM toward northwestern India, modulated by the interaction between moist low-level southwesterly flow from the Arabian Sea and a northwesterly incursion of descending dry air from western central Asia, is in fact a non-steady process. The balance between these two air masses is influenced by the occurrence of transient synoptic-scale features in the region, in turn associated with synoptic-scale dynamics at higher latitudes such as the passage of mid-latitude troughs and the southward propagation of high-PV streamers. The cores of dry and moist air masses can interact very closely during the onset and progression of the monsoon, particularly over northwest India.

A more detailed analysis of the dynamics of this interaction, including the use of Lagrangian trajectories starting over northwest India, confirms the existence of a two-layer pattern with southwesterly moist flow overrun by north-

This article is protected by copyright. All rights reserved. 
westerly dry incursion. The sharpness of the boundary between these two different air masses causes local path and altitude variations to have big effects on air properties. The high-resolution analysis of the dry-air incursion evolution confirms the conceptual model from Parker et al. (2016), with the dry layer essential in preventing the triggering of deep convection while being moistened from below and with shallow convection occurring at low-levels. However, the moistening process and the associated removal of dry air is far from gradual, with dry-air "bursts" affecting the progression of the monsoon. These bursts are associated with the synoptic- and large-scale circulation, as mentioned above, that can induce them to locally flow in directions different from the "classic" northwesterlies.

This analysis also emphasises the role of local diabatic processes, such as moist processes and turbulent mixing, in considerably changing air properties. While it is not straightforward to disentangle the drivers of abrupt changes on thermodynamic quantities along the trajectories, the importance of the Arabian Sea in providing moisture to lowlevel air masses stands out. At certain times during monsoon progression, the majority of the trajectories selected as belonging to the moist low-level flow acquire most of their moisture in a few hours while flowing over the northern stretch of the Arabian Sea. The importance of local evaporation in increasing the moisture content of the low-level flow is instead greatly reduced when the monsoon matures and most of the southwesterly flow is already close to saturation well before reaching India.

A comprehensive analysis of moisture and surface heat fluxes associated with the evolution of the aforementioned airstreams would certainly help in understanding which small-scale processes affect the balance between these different air masses, ultimately shaping ISM progression. An analysis of moisture sources would also complement the research assessing the relevant role of local and remote evaporation/precipitation in the transport of moisture towards the monsoon core region.

This study confirms the dry-air incursion conceptual model in Parker et al. (2016) but also highlights the non-smooth nature of its evolution and the clear link with circulation in the extratropics and the activity of the subtropical westerly jet.

Quantitative diagnostics would be needed to evaluate the extratropical influence on dry-air incursion strength and associated monsoon "bursts". These diagnostics could be applied to long-term reanalysis datasets, to determine how often perturbations to the sub-tropical westerly jet interfere with the monsoon onset. For instance, the computation of vorticity fluxes towards the Indian subcontinent, in a similar fashion to that done by Narsey et al. (2017) for the ...ptralian monsoon, could be an appropriate method of investigation.

(1)

\section{ACKNOWLEDGEMENTS}

INCOMPASS is jointly funded in the UK and India by the Natural Environment Research Council (grants NE/L01386X/1 \& NE/P003117/1) and Ministry of Earth Sciences, under the Monsoon Mission, respectively. The author wish to thank the three anonymous reviewers for their valuable comments and the associated editor Prof G.S. Bhat for the additional insightful discussions.

\section{REFERENCES}

Appenzeller, C. and Davies, H. C. (1992) Structure of stratospheric intrusions into the troposphere. Nature, 358, 570-572.

Arakawa, A. and Lamb, V. (1977) Computational design of the basic dynamical processes of the UCLA general circulation model. Methods in Computational Physics, 17, 173-265.

Berry, G. J. and Reeder, M. J. (2016) The Dynamics of Australian Monsoon Bursts. Journal of the Atmospheric Sciences, 73, 55-69. URL: https://doi.org/10.1175/JAS-D-15-0071.1.

This article is protected by copyright. All rights reserved. 
Bhat, G. S. (2006) The Indian drought of 2002-a sub-seasonal phenomenon? Quarterly Journal of the Royal Meteorological Society, 132, 2583-2602. URL: https ://rmets . onlinelibrary . wiley . com/doi/abs/10.1256/qj .05.13.

Boos, W. and Emanuel, K. (2009) Annual intensification of the Somali jet in a quasi-equilibrium framework: Observational composites. Quarterly Journal of the Royal Meteorological Society, 135, 319-335. URL: https://rmets.onlinelibrary.wiley . $\mathrm{com} / \mathrm{doi} / \mathrm{abs} / 10.1002 / \mathrm{qj} .388$.

Boos, W. and Kuang, Z. (2010) Dominant control of the South Asian monsoon by orographic insulation versus plateau heating. Nature, 463, 218-222.

Boutle, I., Abel, S., Hill, P. and Morcrette, C. (2014) Spatial variability of liquid cloud and rain: Observations and microphysical effects. Quarterly Journal of the Royal Meteorological Society, 140, 583-594.

Charney, J. and Phillips, N. (1953) Numerical integration of the quasi-geostrophic equations for barotropic and simple baroclinic flows. Journal of Meteorology, 10, 71-99.

Donlon, C. J., Martin, M., Stark, J., Roberts-Jones, J., Fiedler, E. and Wimmer, W. (2012) The operational sea surface temperature and sea ice analysis (OSTIA) system. Remote Sensing of Environment, 116, 140-158.

Edwards, J. and Slingo, A. (1996) Studies with a flexible new radiation code. Part I: Choosing a configuration for a large-scale model. Quarterly Journal of the Royal Meteorological Society, 122, 689-719. Doi:10.1002/qj.49712253107.

Essery, R., Best, M. and Cox, P. (2001) 'MOSES 2.2 technical documentation'. HadleyCentre Technical Note. Met Office: Exeter, UK.

Fasullo, J. and Webster, P. J. (2003) A Hydrological Definition of Indian Monsoon Onset and Withdrawal. Journal of Climate, 16, 3200-3211. URL: https://doi .org/10.1175/1520-0442 (2003)016<3200a: AHDOIM>2 .0. C0; 2.

Findlater, J. (1969) A major low-level air current near the Indian Ocean during the northern summer. Quarterly Journal of the Royal Meteorological Society, 95, 362-380. URL: https://rmets.onlinelibrary.wiley.com/doi/abs/10.1002/qj . 49709540409.

Fletcher, J. K., Parker, D. J., Hunt, K. M. R., Vishwanathan, G. and Govindankutty, M. (2018) The Interaction of Indian Monsoon ,Depressions with Northwesterly Midlevel Dry Intrusions. Monthly Weather Review, 146, 679-693. URL: https : //doi .org/ 10.1175/MWR-D-17-0188.1.

Fletcher, J. K., Parker, D. J., Turner, A. G., Menon, A., Martin, G. M., Birch, C. E., Mitra, A. K., Mrudula, G., Hunt, K. M. R., Taylor, C. M., Houze, R. A., Brodzik, S. R. and Bhat, G. S. (2019) The dynamic and thermodynamic structure of the monsoon over southern India: New observations from the INCOMPASS IOP. Quarterly Journal of the Royal Meteorological Society, 0. URL: https://rmets.onlinelibrary.wiley.com/doi/abs/10.1002/qj.3439.

Gadgil, S. (2003) The Indian monsoon and its variability. Annual Review of Earth and Planetary Sciences, 31, 429-467. URL: https://doi.org/10.1146/annurev.earth.31.100901.141251.

Grams, C. M. and Archambault, H. M. (2016) The Key Role of Diabatic Outflow in Amplifying the Midlatitude Flow: A Representative Case Study of Weather Systems Surrounding Western North Pacific Extratropical Transition. Monthly Weather Review, 144, 3847-3869. URL: https://doi .org/10.1175/MWR-D-15-0419.1.

Grant, A. L. M. (2001) Cloud-base fluxes in the cumulus-capped boundary layer. Quarterly Journal of the Royal Meteorological Society, 127, 407-421. URL: https : //rmets . onlinelibrary . wiley . com/doi/abs/10. 1002/qj .49712757209.

Gregory, D. and Rowntree, P. R. (1990) A Mass Flux Convection Scheme with Representation of Cloud Ensemble Characteristics and Stability-Dependent Closure. Monthly Weather Review, 118, 1483-1506. URL: https://doi.org/10.1175/15200493 (1990) 118<1483: AMFCSW>2.0. C0;2.

This article is protected by copyright. All rights reserved. 
Hersbach, H., de Rosnay, P., Bell, B., Schepers, D., Simmons, A., Soci, C., Abdalla, S., Alonso-Balmaseda, M., Balsamo, G., Bechtold, P., Berrisford, P., Bidlot, J.-R., de Boisséson, E., Bonavita, M., Browne, P., Buizza, R., Dahlgren, P., Dee, D., Dragani, R., Diamantakis, M., Flemming, J., Forbes, R., Geer, A. J., Haiden, T., Hólm, E., Haimberger, L., Hogan, R., Horányi, A., Janiskova, M., Laloyaux, P., Lopez, P., Munoz-Sabater, J., Peubey, C., Radu, R., Richardson, D., Thépaut, J.-N., Vitart, F., Yang, X., Zsótér, E. and Zuo, H. (2018) Operational global reanalysis: progress, future directions and synergies with NWP. URL: https://www.ecmwf.int/node/18765.

Hoskins, B. J., Mclntyre, M. E. and Robertson, A. W. (1985) On the use and significance of isentropic potential vorticity maps. Quarterly Journal of the Royal Meteorological Society, 111, 877-946. URL: https://rmets.onlinelibrary.wiley.com/doi/ abs/10.1002/qj. 49711147002.

Hoskins, B. J. and Rodwell, M. J. (1995) A Model of the Asian Summer Monsoon. Part I: The Global Scale. Journal of the Atmospheric Sciences, 52, 1329-1340. URL: https ://doi .org/10.1175/1520-0469(1995) 052<1329: AMOTAS>2.0. C0;2.

Houze, R. A., Rasmussen, K. L., Medina, S., Brodzik, S. R. and Romatschke, U. (2011) Anomalous Atmospheric Events Leading to the Summer 2010 Floods in Pakistan. Bulletin of the American Meteorological Society, 92, 291-298. URL: https : //doi . org/ 10.1175/2010BAMS3173. 1 .

Hunt, K. M. R., Turner, A. G., Inness, P. M., Parker, D. E. and Levine, R. C. (2016) On the Structure and Dynamics of Indian Monsoon Depressions. Monthly Weather Review, 144, 3391-3416. URL: https ://doi . org/10.1175/MWR-D-15-0138.1.

Krishnamurti, T. N., Thomas, A., Simon, A. and Kumar, V. (2010) Desert Air Incursions, an Overlooked Aspect, for the Dry Spells of the Indian Summer Monsoon. Journal of the Atmospheric Sciences, 67, 3423-3441. URL: https://doi.org/10.1175/ 2010JAS3440. 1.

i, C. and Yanai, M. (1996) The Onset and Interannual Variability of the Asian Summer Monsoon in Relation to Land-Sea Thermal Contrast. Journal of Climate, 9, 358-375. URL: https://doi .org/10.1175/1520-0442(1996) 009<0358: TOAIV0>2.0. CO; 2.

Lock, A., Brown, A., Bush, M., Martin, G. and Smith, R. (2000) A new boundary layer mixing scheme. Part I: Scheme description and single-column model tests. Monthly weather review, 128, 3187-3199.

Loveland, T. R., Reed, B. C., Brown, J. F., Ohlen, D. O., Zhu, Z., Yang, L. and Merchant, J. W. (2000) Development of a global land cover characteristics database and IGBP DISCover from $1 \mathrm{~km}$ AVHRR data. International Journal of Remote Sensing, 21, $1303-1330$.

Madonna, E., Wernli, H., Joos, H. and Martius, O. (2014) Warm Conveyor Belts in the ERA-Interim Dataset (1979-2010). Part I: Climatology and Potential Vorticity Evolution. Journal of Climate, 27, 3-26. URL: https ://doi .org/10.1175/JCLI-D-1200720.1 .

Martin, G. M., Brooks, M. E., Johnson, B., Milton, S. F., Webster, S., Jayakumar, A., Mitra, A., Rajan, D. and Hunt, K. M. R. (2019) Forecasting the monsoon on daily to seasonal timescales in support of a field campaign. Quarterly Journal of the Royal Meteorological Society, 0. URL: https://rmets . onlinelibrary . wiley.com/doi/abs/10.1002/qj.3620.

Martius, O. (2014) A Lagrangian Analysis of the Northern Hemisphere Subtropical Jet. Journal of the Atmospheric Sciences, 71, 2354-2369. URL: https://doi.org/10.1175/JAS-D-13-0329.1.

Martius, O., Sodemann, H., Joos, H., Pfahl, S., Winschall, A., Croci-Maspoli, M., Graf, M., Madonna, E., Mueller, B., Schemm, S., Sedláček, J., Sprenger, M. and Wernli, H. (2013) The role of upper-level dynamics and surface processes for the Pakistan flood of July 2010. Quarterly Journal of the Royal Meteorological Society, 139, 1780-1797. URL: https://rmets . onlinelibrary. wiley.com/doi/abs/10.1002/qj. 2082.

Menon, A., Turner, A. G., Martin, G. M. and MacLachlan, C. (2018) Modelling the moistening of the free troposphere during the northwestward progression of Indian monsoon onset. Quarterly Journal of the Royal Meteorological Society, 144, 1152-1168. URL: https://rmets.onlinelibrary.wiley.com/doi/abs/10.1002/qj. 3281.

This article is protected by copyright. All rights reserved. 
Mitra, A. K., Bohra, A. K., Rajeevan, M. N. and Krishnamurti, T. N. (2009) Daily Indian Precipitation Analysis Formed from a Merge of Rain-Gauge Data with the TRMM TMPA Satellite-Derived Rainfall Estimates. Journal of the Meteorological Society of Japan, 87A, 265-279.

Mitra, A. K., Momin, I. M., Rajagopal, E. N., Basu, S., Rajeevan, M. N. and Krishnamurti, T. N. (2013) Gridded daily Indian monsoon rainfall for 14 seasons: Merged TRMM and IMD gauge analyzed values. Journal of Earth System Science, 122, 1173-1182. URL: https://doi.org/10.1007/s12040-013-0338-3.

Narsey, S., Reeder, M. J., Ackerley, D. and Jakob, C. (2017) A Midlatitude Influence on Australian Monsoon Bursts. Journal of Climate, 30, 5377-5393. URL: https://doi .org/10.1175/JCLI-D-16-0686.1.

Noska, R. and Misra, V. (2016) Characterizing the onset and demise of the Indian summer monsoon. Geophysical Research Letters, 43, 4547-4554. URL: https : //agupubs . onlinelibrary. wiley.com/doi/abs/10. 1002/2016GL068409.

Panagi, P. (2011) NDdiag: A Fortran90 program to compute diagnostics on pressure levels from Unified Model data on model levels. Accessed from https://puma.nerc.ac.uk/trac/UM_TOOLS/wiki/NDdiag.

Parker, D. J., Willetts, P., Birch, C., Turner, A. G., Marsham, J. H., Taylor, C. M., Kolusu, S. and Martin, G. M. (2016) The interaction of moist convection and mid-level dry air in the advance of the onset of the Indian monsoon. Quarterly Journal of the Royal Meteorological Society, 142, 2256-2272. URL: https ://rmets.onlinelibrary. wiley.com/doi/abs/10.1002/qj.2815.

Pfahl, S., Madonna, E., Boettcher, M., Joos, H. and Wernli, H. (2014) Warm Conveyor Belts in the ERA-Interim Dataset (1979-2010). Part II: Moisture Origin and Relevance for Precipitation. Journal of Climate, 27, 27-40. URL: https: //doi.org/10.1175/JCLI-D-13-00223.1.

Rodwell, M. J. and Hoskins, B. J. (1996) Monsoons and the dynamics of deserts. Quarterly Journal of the Royal Meteorological Society, 122, 1385-1404. URL: https : //rmets . onlinelibrary . wiley . com/doi/abs/10.1002/qj . 49712253408.

Shenoi, S. S. C., Shankar, D. and Shetye, S. R. (2002) Differences in heat budgets of the near-surface Arabian Sea and Bay of Bengal: Implications for the summer monsoon. Journal of Geophysical Research: Oceans, 107, 5-1-5-14. URL: https:// agupubs.onlinelibrary.wiley.com/doi/abs/10.1029/2000JC000679.

Smith, R. (1990) A scheme for predicting layer clouds and their water content in a general circulation model. Quarterly Journal of the Royal Meteorological Society, 116, 435-460.

lemann, H., Schwierz, C. and Wernli, H. (2008) Interannual variability of Greenland winter precipitation sources: Lagrangian moisture diagnostic and North Atlantic Oscillation influence. Journal of Geophysical Research: Atmospheres, 113. URL: https://agupubs . onlinelibrary.wiley.com/doi/abs/10.1029/2007JD008503.

Sprenger, M. and Wernli, H. (2015) The LAGRANTO Lagrangian analysis tool - version 2.0. Geoscientific Model Development, 8, 2569-2586. URL: https://www.geosci-model-dev.net/8/2569/2015/.

Stratton, R. A., Senior, C. A., Vosper, S. B., Folwell, S. S., Boutle, I. A., Earnshaw, P. D., Kendon, E., Lock, A. P., Malcolm, A., Manners, J., Morcrette, C. J., Short, C., Stirling, A. J., Taylor, C. M., Tucker, S., Webster, S. and Wilkinson, J. M. (2018) A Pan-African Convection-Permitting Regional Climate Simulation with the Met Office Unified Model: CP4-Africa. Journal of Climate, 31, 3485-3508. URL: https://doi.org/10.1175/JCLI-D-17-0503.1.

Turner, A. and Annamalai, H. (2012) Climate change and the South Asian summer monsoon. Nature Climate Change, 2, $587-595$.

Turner, A. G., Bhat, G. S., Martin, G. M., Parker, D. J., Taylor, C. M., Mitra, A. K., Tripathi, S. N., Milton, S., Rajagopal, E. N., Evans, J. G., Morrison, R., Pattnaik, S., Sekhar, M., Bhattacharya, B. K., Madan, R., Govindankutty, M., Fletcher, J. K., Willetts, P. D., Menon, A., Marsham, J. H., the INCOMPASS team, Hunt, K. M. R., Chakraborty, T., George, G., Krishnan, M., Sarangi, C., BelušiĆ, D., Garcia-Carreras, L., Brooks, M., Webster, S., Brooke, J. K., Fox, C., Harlow, R. C., Langridge, J. M., Jayakumar, A., Böing, S. J., Halliday, O., Bowles, J., Kent, J., O'Sullivan, D., Wilson, A., Woods, C., Rogers, S., Smout-Day, R., Tiddeman, D., Desai, D., Nigam, R., Paleri, S., Sattar, A., Smith, M., Anderson, D., Bauguitte, S., Carling, R., Chan, C., Devereau, S., Gratton, G., MacLeod, D., Nott, G., Pickering, M., Price, H., Rastall, S., Reed, C., Trembath, J., Woolley, A., Volonté, A. and New, B. (2019)

This article is protected by copyright. All rights reserved. 
Interaction of Convective Organisation with Monsoon Precipitation, Atmosphere, Surface and Sea: the 2016 INCOMPASS field campaign in India. Quarterly Journal of the Royal Meteorological Society, 0. URL: https ://rmets . onlinelibrary . wiley . com/doi/abs/10.1002/qj.3633.

Čampa, J. and Wernli, H. (2012) A PV Perspective on the Vertical Structure of Mature Midlatitude Cyclones in the Northern Hemisphere. Journal of the Atmospheric Sciences, 69, 725-740. URL: https ://doi .org/10.1175/JAS-D-11-050.1.

Vellore, R. K., Kaplan, M. L., Krishnan, R., Lewis, J. M., Sabade, S., Deshpande, N., Singh, B. B., Madhura, R. K. and Rama Rao, M. V. S. (2016) Monsoon-extratropical circulation interactions in Himalayan extreme rainfall. Climate Dynamics, 46, 35173546. URL: https://doi .org/10.1007/s00382-015-2784-x.

Volonté, A., Clark, P. A. and Gray, S. L. (2018) The role of mesoscale instabilities in the sting-jet dynamics of windstorm Tini. Quarterly Journal of the Royal Meteorological Society, 144, 877-899. URL: https://rmets.onlinelibrary.wiley.com/doi/ $\mathrm{abs} / 10.1002 / \mathrm{qj} \cdot 3264$.

Walters, D., Baran, A., Boutle, I., Brooks, M., Earnshaw, P., Edwards, J., Furtado, K., Hill, P., Lock, A., Manners, J., Morcrette, C., Mulcahy, J., Sanchez, C., Smith, C., Stratton, R., Tennant, W., Tomassini, L., Van Weverberg, K., Vosper, S., Willett, M., Browse, J., Bushell, A., Dalvi, M., Essery, R., Gedney, N., Hardiman, S., Johnson, B., Johnson, C., Jones, A., Mann, G., Milton, S., Rumbold, H., Sellar, A., Ujiie, M., Whitall, M., Williams, K. and Zerroukat, M. (2017) The Met Office Unified Model Global Atmosphere 7.0/7.1 and JULES Global Land 7.0 configurations. Geoscientific Model Development Discussions, 2017, 1-78. URL: https://www .geosci-model-dev-discuss .net/gmd-2017-291/.

Webster, P. J., Magaña, V. O., Palmer, T. N., Shukla, J., Tomas, R. A., Yanai, M. and Yasunari, T. (1998) Monsoons: Processes, predictability, and the prospects for prediction. Journal of Geophysical Research: Oceans, 103, 14451-14510. URL: https: //agupubs.onlinelibrary.wiley.com/doi/abs/10.1029/97JC02719.

Wernli, H. and Davies, H. C. (1997) A lagrangian-based analysis of extratropical cyclones. I: The method and some applications. Quarterly Journal of the Royal Meteorological Society, 123, 467-489. URL: https://rmets.onlinelibrary.wiley.com/doi/ abs/10.1002/qj.49712353811.

(1) Wernli, H. and Sprenger, M. (2007) Identification and ERA-15 Climatology of Potential Vorticity Streamers and Cutoffs near the Extratropical Tropopause. Journal of the Atmospheric Sciences, 64, 1569-1586. URL: https://doi.org/10.1175/ JAS3912. 1.

Wilson, D. R. and Ballard, S. P. (1999) A microphysically based precipitation scheme for the UK meteorological office unified model. Quarterly Journal of the Royal Meteorological Society, 125, 1607-1636. URL: https ://rmets . onlinelibrary.wiley . com/doi/abs/10.1002/qj.49712555707.

Wilson, D. R., Bushell, A. C., Kerr-Munslow, A. M., Price, J. D. and Morcrette, C. J. (2008) PC2: A prognostic cloud fraction and condensation scheme. I: Scheme description. Quarterly Journal of the Royal Meteorological Society: A journal of the atmospheric sciences, applied meteorology and physical oceanography, 134, 2093-2107.

Wood, N., Staniforth, A., White, A., Allen, T., Diamantakis, M., Gross, M., Melvin, T., Smith, C., Vosper, S., Zerroukat, M. et al. (2014) An inherently mass-conserving semi-implicit semi-Lagrangian discretization of the deep-atmosphere global nonhydrostatic equations. Quarterly Journal of the Royal Meteorological Society, 140, 1505-1520.

Xavier, P. K., Marzin, C. and Goswami, B. N. (2007) An objective definition of the Indian summer monsoon season and a new perspective on the ENSO-monsoon relationship. Quarterly Journal of the Royal Meteorological Society, 133, 749-764. URL: https://rmets . onlinelibrary.wiley.com/doi/abs/10.1002/qj. 45.

This article is protected by copyright. All rights reserved. 